Quaestio facti. Revista Internacional sobre Razonamiento Probatorio

Quaestio facti. International Journal on Evidential Legal Reasoning

Vol. 1 | 2020 pp. 201-246

Madrid, 2020

DOI: $10.33115 /$ udg_bib/qf.i1.22288

Marcial Pons Ediciones Jurídicas y Sociales

(C) José Luis Ramírez Ortiz

ISSN: 2604-6202

Recibido: 24/01/2019 | Aceptado: 28/02/2019

\title{
EL TESTIMONIO ÚNICO DE LA VÍCTIMA EN EL PROCESO PENAL DESDE LA PERSPECTIVA DE GÉNERO
}

\author{
José Luis Ramírez Ortiz \\ Magistrado, Audiencia Provincial de Barcelona \\ joseluisramirezortiz@gmail.com \\ jose.ramirez@poderjudicial.es
}

ABSTRACT: El autor de este trabajo analiza qué puede aportar la perspectiva de género en el proceso penal en los supuestos de declaración de la víctima como prueba única. Alcanza la conclusión de que en la fase de enjuiciamiento su valor epistémico, suministrando nuevas máximas de la experiencia que permiten valorar las pruebas sin prejuicios, no puede subsanar la insuficiencia de un medio probatorio sobre cuya base, cuando no se encuentra corroborado, no puede entenderse válidamente desvirtuada la presunción de inocencia. No obstante lo cual, destaca que, en estos casos, en la fase investigativa la perspectiva de género adquiere una notable utilidad heurística, tanto para construir adecuadamente las hipótesis inculpatorias como para buscar otras fuentes que sirvan para corroborar el testimonio en el futuro juicio oral.

PALABRAS CLAVE: Testimonio único de la víctima; corroboración; presunción de inocencia; perspectiva de género; estereotipos; libre valoración de la prueba y prueba legal.

\section{SINGLE VICTIM'S TESTIMONY AND GENDER PERSPECTIVE IN THE CRIMINAL PROCEDURE}

ABSTRACT: The author of this paper analyses if gender perspective is useful in criminal proceedings to asses the single victim's testimony in order to reach a conviction. The conclusion is negative. Gender perspective provides tools to evaluate evidence without prejudices, but in spite of the epistemic values of those tools, the uncorroborated evidence of a single witness is not sufficient, in any case, for proof of guilt in a criminal proceeding as it cannot distort the presumption of innocence. 
However, the author highlights that in the pretrial investigation, gender perspective acquires a remarkable heuristic utility, both to adequately construct the inculpatory hypotheses and to collect evidence that will be use to corroborate the witness testimony in the future trial.

KEYWORDS: Single victim's testimony; corroboration; presumption of innocence; gender perspective; stereotypes; free proof and legal proof.

SUMARIO: 1. Perspectiva de género: la utilidad de una herramienta analítica obligada.-2. Testimonio único, prueba legal y libre valoración probatoria: algunos equívocos.-3. El testimonio único ante la presunción de inocencia. 3.1. Codificación y versión irracionalista de la libre convicción. 3.2. Constitucionalismo y versión racionalista de la libre convicción. 3.3. La versión racionalista exige la corroboración del testimonio.— - El testimonio único ante la violencia de género: nuevos equívocos. 4.1. El riesgo de impunidad. 4.2. La sobrevaloración de la presunción de inocencia. 4.3. Las diferentes posiciones procesales de quien afirma ser víctima y acusado. 4.4. La atribución a la víctima de la condición de testigo especialmente cualificado. 4.5. La suficiencia de la coherencia del relato. 4.6. La existencia de una situación de asimetría o dominación.-5. Función epistémica y función heurística de la perspectiva de género. 5.1. La perspectiva de género: sesgos y estereotipos. 5.2. Función epistémica y función heurística. 5.3. Los estereotipos en el enjuiciamiento. 5.4. Los estereotipos en la investigación. 5.5. La dominación: elementos de contexto relevantes.-6. Algunas fuentes de corroboración controvertidas: periciales de fiabilidad y testificales de referencia. 6.1. Pruebas periciales de fiabilidad del testimonio de personas adultas. 6.2. Declaraciones testificales de referencia.-7. Conclusiones.

\section{PERSPECTIVA DE GÉNERO: LA UTILIDAD DE UNA HERRAMIENTA ANALÍTICA OBLIGADA ${ }^{1}$}

La desigualdad entre hombres y mujeres dentro de la organización política constituye un problema estructural de raíces históricas que se encuentra en la base de conflictos de diversa tipología y se refleja en ámbitos muy heterogéneos. Dicha desigualdad es fruto de unas condiciones materiales concretas, pero también de la representación constitutiva y legitimadora del orden social, consecuencia de tales condiciones, que asigna roles específicos a unas y a otros. La asunción, aun tácita, de los referidos roles sirve para salvaguardar la integridad de ese orden desigual y para perpetuar su subsistencia. Por ello, en el análisis de la realidad es esencial introducir una herramienta conceptual que parta de la conciencia de la situación histórica y presente en que se desenvuelve la mujer en el sistema.

La categoría es el género, que define el Convenio de Estambul ${ }^{2}$ como los «papeles, comportamientos, actividades y atribuciones socialmente construidos que una

1 En este trabajo se utilizará el género gramatical masculino para referirse a mujeres y a hombres, como aplicación de la ley lingüística de la economía expresiva. Cuando la oposición de sexos sea un factor relevante en el contexto se explicitarán ambos géneros.

2 Convenio del Consejo de Europa sobre prevención y lucha contra la violencia contra la mujer y la violencia doméstica, hecho en Estambul el 11 de mayo de 2011. Instrumento de ratificación publicado en $B O E$ núm. 137, de 6 de junio de 2014, 
sociedad concreta considera propios de mujeres o de hombres». El instrumento, la perspectiva de género, que se presenta como criterio para analizar y comprender lo social y sus instituciones.

En el ámbito jurídico la perspectiva de género puede servir para desvelar aquellas instituciones, reglas y prácticas del derecho que crean, legitiman y perpetúan la discriminación, con el propósito de derogarlas, transformarlas y/o sustituirlas por otras. Y así, numerosos instrumentos internacionales universales y regionales, partiendo de la constatación de que las mujeres siguen siendo objeto de importantes discriminaciones que violan los principios de la igualdad de derechos y del respeto a la dignidad humana, imponen a los Estados parte que adopten todas las medidas adecuadas para corregir esta situación. A tal fin, propugnan la eliminación de los prejuicios y las prácticas consuetudinarias y de cualquier otra índole que estén basados en la idea de la inferioridad o superioridad de cualquiera de los sexos o en funciones estereotipadas de hombres y mujeres ${ }^{3}$.

Su proyección sobre la vertiente penal requiere de algún complemento, pues no se trata de una rama del derecho tendencialmente orientada al cambio social, ya que su función primordial es la de mantener a raya los excesos punitivos del Estado, al menos en los ordenamientos constitucionales. Como estos parten de un principio de sana desconfianza hacia el ejercicio del poder penal por los sujetos institucionales públicos, en tanto que proclives al abuso y a la arbitrariedad, articulan diversos mecanismos para prevenir, corregir y sancionar dichos excesos. Esos mecanismos cristalizan en un amplio elenco de garantías penales, procesales y sustantivas cuya función central es la preservación de la libertad del ciudadano. En consecuencia, aun cuando, indudablemente, quepa extraer rendimientos fructíferos de la perspectiva de género en el análisis e interpretación de la ley penal y de sus instituciones, nunca ha de perderse de vista la función última de límite del poder público de esta rama del derecho estatal.

En lo que sigue, me centraré en un único aspecto: qué puede aportar esta perspectiva, y en qué grado, al problema del testimonio único. No abordaré, por tanto, la utilidad de la herramienta conceptual en la creación e interpretación de la norma sustantiva, tanto desde la óptica mujer-víctima como desde el prisma mujer-encausada, ni su funcionalidad en el ámbito asistencial (v.gr. derechos prestacionales de quienes afirman ser víctimas), ni en todo el espectro procesal (v.gr: evitación de victimizaciones secundarias, medidas cautelares, ejecución de la pena, etc.), contextos en los que su rendimiento parece más evidente.

\footnotetext{
3 Destacan la Convención sobre la Eliminación de todas las Formas de Discriminación contra la Mujer (CEDAW, por sus siglas en inglés), aprobada por la Asamblea General de las Naciones Unidas el 18 de diciembre de 1979, y las Recomendaciones Generales que el Comité de expertos que crea la CEDAW hace a los Estados; la Convención Interamericana para Prevenir, Sancionar y Erradicar la Violencia contra la Mujer "Convención De Belém Do Pará", 9 de junio de 1994; y el Convenio de Estambul.
} 


\section{TESTIMONIO ÚNICO, PRUEBA LEGAL Y LIBRE VALORACIÓN PROBATORIA: ALGUNOS EQUÍVOCOS}

La doctrina jurisprudencial suele afirmar ${ }^{4}$ que la regla «testis unus testis nulllus» (testigo único, testigo nulo), con arreglo a la cual el testimonio de una sola persona es insuficiente para condenar a alguien como autor de un hecho delictivo, constituye un residuo del derecho histórico vinculado a los sistemas de prueba legal o tasada. Este modelo atribuía a cada prueba un valor fijo o predeterminado ${ }^{5}$, de manera que el juez, quien no podía tomar en consideración determinados medios probatorios, se limitaba a hacer con las pruebas permitidas operaciones aritméticas, sumando y restando pruebas, para llegar a una conclusión con independencia de su convicción personal.

La norma recorre el derecho romano, atraviesa las distintas tradiciones religiosas, se recibe en el derecho medieval y sigue desplegando sus efectos en el Estado moderno prácticamente hasta el siglo xviII. Ecos de ella pueden verse en el Código de Justiniano $(4,20,9)^{6}$, en la Biblia, tanto en el Antiguo como en el Nuevo Testamento (véase, entre otros, Deuteronomio, 19,157, y Evangelio de San Mateo, 18, 16 ${ }^{8}$ ), así como en el derecho canónico ${ }^{9} \mathrm{y}$ en las Partidas ${ }^{10}$. También en el proceso inquisitivo se contempla esta regla limitativa, y así, en el manual de inquisidores de Nicolao Eymerico, redactado a mediados del siglo $\mathrm{XIV}^{\mathrm{II}} \mathrm{y}$ que fue aplicado hasta la abolición de la Inquisición en 1834, se exigía para "fallar en sentencia definitiva contra el hereje» el testimonio de dos personas "puesto que nos parece más conforme a equidad no considerar esta prueba como plena». De modo más específico, tratándose de la persona que afirma ser víctima, de los textos históricos se deduce, además, su inidoneidad para declarar en calidad de testigo, en tanto, en sentido propio, tendrían la condición de parte. Así es de ver en el Digesto 22, 5, 10 («Ningún testigo se entiende ser idóneo en su propia causa») ${ }^{12}$.

${ }^{4}$ Entre muchas otras, Sentencia de la Sala de lo Penal del Tribunal Supremo español (STS) 88/2015, de 17 de febrero (ponente Sr. Martínez Arrieta, ROJ: STS 694/2015), cuando destaca que en el «moderno proceso penal» la regla no tiene cabida.

${ }^{5}$ Valor, que podía ser cero.

${ }^{6}$ Constitución de Constantino del ańo 334, en la que se establece que no se oiga el testimonio de un solo testigo, aunque se trate de alguien perteneciente a la curia. Ciertamente, no encontramos una norma expresa análoga en el derecho clásico romano, pero existen razones para afirmar que se dudaba de su suficiencia probatoria o, cuando menos, que el testimonio único se contemplaba con recelo (v.gr. Digesto 22, 5, 12 «Cuando no se señala el número de testigos, bastan incluso dos...» o 22, 5, 3 «...no se debe dar fe sin más a una sola clase de pruebas recibidas...»).

7 «No se tomará en cuenta a un solo testigo contra ninguno en cualquier delito ni en cualquier pecado, en relación con cualquiera ofensa cometida. Sólo por el testimonio de dos o tres testigos se mantendrá la acusación».

8 «Mas si no te oyere, toma aún contigo a uno o dos, para que en boca de dos o tres testigos conste toda palabra».

9 Véanse diversas referencias en SANCinetTi, M., 2013.

10 Partida III, Título XVI, Ley 32, que exigía, como regla general, dos testigos, número que podía ser mayor según los casos.

11 Eymerico, N., 1503: 11 y ss.

12 Nieva Fenoll se ha referido al contrasentido que encierra la expresión, común en la cultura latina, testigo-víctima, pues quien padece los efectos de un delito no es un tercero ajeno al objeto del 
De los ejemplos precedentes cabría extraer la conclusión de que el aforismo «testis unus testis nullus» describiría la regla de un derecho antiguo, periclitado, a superar por la modernidad. Sin embargo, lo cierto es que históricamente no han existido modelos puros de prueba legal ${ }^{13}$, del mismo modo que tampoco han existido modelos puros de libre valoración ${ }^{14}$, sino modelos con una mayor o menor presencia de reglas de valoración y de suficiencia e insuficiencia probatoria. Los sistemas puros, de uno y otro signo, no dejan de ser idealizaciones, modelos límite.

Bajo ese ángulo no es necesariamente incongruente que en el modelo tendencialmente orientado a la libre valoración probatoria defendido por un movimiento tan revolucionario y racionalista como el ilustrado se mantuviera la consideración de que el testigo único era probatoriamente insuficiente para la justificación del hecho delictivo ${ }^{15}$.

La Ilustración promovió un sistema de valoración probatoria racional que debía desterrar, en palabras de BenthAM «las reglas que colocan al juez en la necesidad de pronunciar una sentencia contra su propia convicción» ${ }^{16}$. Ahora bien, la convicción no se consideró como la intuición o corazonada sobre lo sucedido, que podrían degenerar en error o puro arbitrio, sino como el producto de una actividad racional. Ello exigía descartar reglas de prueba legal contraepistémicas (que, si bien dotadas de racionalidad instrumental en tanto que reflejaban un determinado orden social y lo reforzaban ${ }^{17}$, carecían de la racionalidad instrumental que exigía el nuevo orden que pretendían imponer los ilustrados), pero no aquellas funcionales para la prevención del error y el abuso.

El mismo Bentham alertó de los riesgos del testimonio único, por más que quien lo prestara fuera una persona de total confianza, destacando que la fuerza probatoria del testimonio dependía del número de testigos y de la concurrencia de otras circuns-

juicio, por lo que su denominación como testigo es incorrecta. A su juicio, la figura tiene raigambre inquisitiva, pues al constituirse el juez en parte acusadora, el encaje que quedaba a la víctima en el proceso no podía ser del de parte, por lo que entraba en él como testigo. Tal contradicción, no obstante, no ha sido resuelta en nuestro derecho, que no regula la declaración de partes en el juicio oral, por lo que quien afirma ser víctima, pese a tener un evidente interés directo en la causa, sigue declarando como testigo. Véase Nieva Fenoll, J., 2010: 247 y ss.

13 Véase, a tal efecto, Nieva Fenoll, J., 2010: 58 y ss.

14 El valor preestablecido de cierta clase de documentos públicos constituye un ejemplo.

15 Véase Sancinetti, M., 2013.

16 Bentham, J., 1823: 61 y ss.

17 Así, el extenso catálogo de inhabilidades para testificar contenido en la Partida III, tít. XVI: personas de mala fama, condenados por falso testimonio, falsificadores, envenenadores, abortistas, asesinos, adúlteros, libertinos, violadores, apóstatas, incestuosos, enajenados mentales, ladrones, proxenetas, tahúres, lesbianas travestidas, pobres de solemnidad, mentirosos, incumplidores de sentencias, judíos, musulmanes, herejes (Ley 8), presos, toreros, prostitutas, libertos en pleito de su antiguo señor (Ley 10), siervos (salvo excepciones y bajo tormento, Leyes 12 y 13), así como en pleitos hereditarios, a mujeres y hermafroditas que «tirassen mas a varon que a muger» (Ley 17). Cita tomada de Nieva Fenoll, J., 2017. 
tancias externas de refuerzo ${ }^{18}$. Autores como Montesquieu, Beccaria o Pagano se pronunciaron en la misma línea. El primero sostuvo ${ }^{19}$ :

Las leyes que condenan a muerte a un hombre por la deposición de un solo testigo son funestas a la libertad. La razón pide que haya dos, porque un testigo que afirma y un acusado que niega forman un empate, y hace falta un tercero que decida, Los griegos y los romanos exigían un voto más para condenar: nuestras leyes francesas requieren dos. Los griegos pretendían que su uso era de origen divino; pero mejor lo sería el nuestro.

En cuanto a Beccaria, afirmó: «Siempre es necesario más de un testigo, porque en tanto que uno afirma y otro niega no hay nada cierto, y prevalece el derecho que cada cual tiene a ser creído inocente» ${ }^{20}$.

Finalmente, Pagano ${ }^{2 \mathrm{I}}$ nos dice:

«Es menester que los testimonios sean dos por lo menos, para establecer la prueba suficiente para imponer una pena al acusado...la razón de ese precepto no es la que aduce Montesquieu, o sea que un testigo único no hace prueba porque su dicho está contrabalanceado por el del acusado... pues el acusado que niega está compensado con el acusador que afirma, y el dicho de uno es destruido por el del otro. La duda del juez debe resolverse mediante los testimonios». Y se pregunta: "ipor qué se requiere en los testimonios siempre el número plural», para responder: «La verdad es como la luz, que centellea en el contraste de dos cuerpos que se topan recíprocamente. ¿Qué otro medio más seguro hay para conocer la verdad o falsedad de un dicho que confrontarlo con el de otro testigo?....La confrontación es la piedra fundamental de la verdad, y donde el sistema de pruebas criminales desconoce esta confrontación, es el azar más que la verdad lo que dirige las sentencias de los jueces».

La codificación optó por derogar la mayor parte de las reglas legales de valoración probatoria $^{22}$, con la finalidad de dejar el más amplio espacio posible a la libertad de apreciación del juez. Pero al hacerlo indiferenciadamente, sin distinguir entre pruebas legales positivas (aquellas en presencia de las cuales la ley obliga al juez que considere probada la hipótesis acusatoria, aun cuando no esté convencido) y pruebas legales negativas (aquellas en ausencia de las cuales la ley prescribe al juez que considere no probada la hipótesis acusatoria, aunque esté convencido de su viabilidad), acabó desactivando un entramado de reglas que venían desempeñando en la práctica un valioso papel de garantía procesal frente a la arbitrariedad y el decisionismo. Como ha puesto de relieve Ferrajoli ${ }^{23}$, si bien fue un avance partir de la base de que ninguna prueba legalmente predeterminada podía ser considerada suficiente por

${ }_{18}$ Así se deduce del hecho de que reconociera que la información proporcionada por un testigo ideal arquetípico (de irreprochable fama y contradictoria y exhaustivamente interrogado) pudiera ser falsa, Benthanm, J., 1823: 62).

19 Montesquieu, C., 1748: XII, II, 173.

20 Beccaria, C., 1764: 26 y 27.

21 Pagano, F., 1803: 99 y ss.

22 Aunque hubo resistencias, como puede verse en el Proyecto de Código Criminal español de 1830, que exigía, para que la testifical pudiera ser considerada prueba completa la concurrencia de dos o más testigos presenciales y «libres de toda excepción», teniendo el valor de simple prueba auxiliar la declaración del ofendido «cuando el delito se hubiera cometido de noche, en despoblado u ocultamente». En Ortego Gil, P., 2015: 126 y ss.

23 Ferrajoli, L., 2006: 147 y ss. 
sí sola para garantizar la verdad de la conclusión en contraste con la libre convicción del juez, no lo fue el aceptar también que el simple convencimiento de aquel podía ser considerada bastante a tal fin. Algunas de las pruebas legales negativas constituían una garantía contra la convicción errónea o arbitraria de la culpabilidad, asegurando normativamente la necesidad de la prueba y la presunción de inocencia hasta prueba en contrario. Ya lo había apuntado PAGANo al afirmar: «...la ley no le ordena al juez que condene al acusado con dos testigos, sino que sólo se lo permite. Con sólo uno no puede condenarlo, pero con dos pueden también absolverlo» ${ }^{24}$.

Lamentablemente, liberada de ataduras, en un contexto judicial en el que no existía una cultura de la motivación de las decisiones ${ }^{25}$, la ansiada «libre valoración» se convirtió en un proceso opaco que subjetivizó el criterio indicador de cuándo se había conseguido la prueba del hecho a través de la doctrina de la «íntima convicción", lo que se tradujo en irracionalidad e intuicionismo. Y lo cierto, es que esa consecuencia no era ni siquiera normativamente obligada, pues la «libre valoración» permitía una clara lectura en negativo (como antítesis de un modelo extremo de predeterminación de los valores probatorios al margen del caso) pero dejaba abierto su contenido positivo ${ }^{26}$ (cómo habían de determinarse esos valores probatorios). Del mismo modo, tampoco era consecuencia obligada el hecho de que de la derogación de las pruebas legales negativas hubiera de seguirse necesariamente la posibilidad de que en la praxis judicial el testimonio único fuera probatoriamente bastante, pues de la ausencia de reglas concretas sobre la suficiencia de un determinado medio de prueba no se sigue que su sola concurrencia pueda llenar las exigencias del estándar acreditativo de referencia.

\section{EL TESTIMONIO ÚNICO ANTE LA PRESUNCIÓN DE INOCENCIA}

\subsection{Codificación y versión irracionalista de la libre convicción}

La Ley de Enjuiciamiento Criminal espańola, aprobada en el año 1882 (en lo sucesivo, Lecrim) introdujo un precepto que con frecuencia se destaca como paradigmático del modelo de libre valoración. Así, el art. 741 Lecrim señala que el juez ha de dictar sentencia «....apreciando según su conciencia las pruebas practicadas en

24 Obra citada en nota a pie de página 11.

25 Como señala Alonso Romero, P., 2008: 99 y ss, la ausencia de motivación era «el régimen asentado en la doctrina del ius commune, cuyos cultivadores desde la Baja Edad Media se habían manifestado mayoritariamente contrarios a la motivación, considerándola imprudente e incluso temeraria, por la apertura eventual de nuevos frentes de conflicto y el abuso de impugnaciones a que podría dar lugar, además de un dispendio inútil de energía para el juez». En esta línea, la motivación llegó a ser prohibida por la Ley VIII, tít. XV, Lib. XI de la Novísima Recopilación. Por su parte, en el sistema del common law los jurados no motivas las decisiones sobre los hechos, lo que hace especialmente importante las instrucciones que el juez ha de impartirles.

${ }^{26}$ Igartua Salaverria, J,. 1995: 154 y ss. 
el juicio, las razones expuestas por la acusación y la defensa y lo manifestado por los mismos procesados...». La lectura de la norma evidencia que, efectivamente, no se impusieron trabas ni restricciones valorativas al juzgador. Pero esa ausencia de exigencias nada indicaba tampoco acerca de la necesidad de la racionalidad de la valoración. En otros términos: la literalidad de la norma amparaba tanto una versión racionalista de la libre valoración, intersubjetivamente controlable, como una versión irracionalista, estrictamente subjetiva, de la misma. Por diversas razones, que analiza IGARTuA SalaverRÍ́ ${ }^{27}$, se acabó imponiendo la segunda, que prolongó su vigencia durante algo más de un siglo.

Como señala el citado autor, ejemplo de la asunción de esa versión irracionalista, ya entrados en el año 1981, lo encontramos en las alegaciones del Fiscal General del Estado a un recurso de amparo, que reproducen la Sentencia del Tribunal Constitucional (en lo sucesivo, TC) 31, de 28 de julio. Dichas alegaciones compendian la doctrina de la Sala de lo Penal del Tribunal Supremo (en lo sucesivo, TS) sobre la materia y que, por su elocuencia, conviene traer a colación:

...de acuerdo con la reiterada jurisprudencia del Tribunal Supremo «lo declarado probado por las Audiencias deviene indestructible e invulnerable» (Sentencia de 15 de marzo de 1980) y la facultad de apreciación de la prueba en conciencia que concede a los Tribunales el art. 741 de la L. E. Crim., no exige explicación ni razonamiento (Sentencia de 11 de octubre de 1978), de modo que el juzgador, a la hora de apreciar las pruebas practicadas, las alegaciones de las partes y las declaraciones o manifestaciones del acusado, lo hará no ya sin reminiscencias de valoración tasada o predeterminada por la Ley, o siguiendo las reglas de la sana crítica, o de manera simplemente lógica o racional sino de un modo tan libérrimo y omnímodo que no tiene más freno a su soberana facultad valorativa que el de proceder al análisis y a la consecutiva ponderación con arreglo a su propia conciencia, a los dictados de su razón analítica y a una intención que se presume siempre recta e imparcial (Sentencia de 10 de febrero de 1978).

En suma, por lo que nos atañe, la ausencia en la Lecrim de reglas de exclusión del valor acreditativo del testimonio único como prueba que por sí sola legitima la condena se combinó con una praxis jurisprudencial, avalada por el TS, que permitía, de acuerdo con el paradigma de la «íntima convicción», que si el Tribunal, tras oír al testigo y al acusado, quedaba «íntimamente persuadido» de la culpabilidad del segundo, podía dar por acreditados los hechos objeto de acusación sin mayores explicaciones. Que un sistema así configurado, abierto al arbitrio más absoluto, perdurase en el tiempo sin graves convulsiones (no debe olvidarse que gran parte de las reglas de prueba legal tienen su origen en la desconfianza hacia la regular actuación de los jueces) puede explicarse nuevamente en la racionalidad instrumental: si en el primer Estado liberal el poder judicial no dejaba de ser un apéndice del poder ejecutivo integrado por individuos de un colectivo de marcado perfil «monoclase», del que participaban el resto de aparatos del Estado ${ }^{28}$, quedaba facilitada cierta homogeneidad no solo en la interpretación y aplicación de la ley, sino también en la valoración probatoria, pues había conciencia de clase acerca de qué valores generales,

27 Ibid:: 65 y ss. Tirant lo Blanch.

28 Este fenómeno ha sido analizado con profundidad por Andrés IBÁñez, P., 2011: 31 y ss.. 
funcionales para el mantenimiento del orden social, debían defenderse, aun a costa de la verdad del caso concreto $^{29}$.

\subsection{Constitucionalismo y versión racionalista de la libre convicción}

La aprobación de la Constitución de 1978 (en lo sucesivo, CE) supuso la introducción del derecho a la presunción de inocencia (art. 24.2 CE) y, tras la asunción cultural por la praxis jurisprudencial del alcance de ese derecho fundamental, una modificación del entendimiento de ciertos tópicos probatorios que precisaban de una profunda actualización. Así, el principio «in dubio pro reo» dejaba de ser una simple regla moral de prudencia dirigida al juzgador, de quien se esperaba cierta magnanimidad ${ }^{30}$, y se convertía no solo en un derecho fundamental directamente exigible sino en el principio estructural del sistema procesal. En definitiva, si la culpabilidad del encausado era una mera hipótesis que no precedía al proceso, sino que era su consecuencia, no es que hubiera de ser "considerado" como inocente hasta que el proceso concluyera por sentencia firme, sino que hasta ese momento "era» inocente. Y solo podía dejar de serlo cuando la sentencia firme que diera por acreditada tal hipótesis lo hiciera más allá de toda duda razonable. Pero, además, las exigencias motivadoras que impuso el art. 120.3 CE, se incorporaron al contenido constitucional de la presunción de inocencia, de la que han acabado formando parte inseparable. Así lo afirmó la STC 145/05, de la que se sigue que para desvirtuar aquella no solo se precisa la existencia de prueba de cargo, sino que dicha prueba ha de aparecer suficientemente razonada en sentencia, exigiendo del juzgador una explícita exposición de los elementos de convicción que sustentan la declaración de hechos probados.

Fruto de ello, había de estimarse definitivamente superada la vieja doctrina jurisprudencial que afirmaba que la facultad de apreciación de la prueba en conciencia no exigía explicación ni razonamiento, pues el juzgador de instancia gozaba de absoluta libertad a tal efecto (de libérrima y omnímoda, llegó a ser calificada). La racionalidad instrumental propia de un nuevo orden social basado en derechos fundamentales constituidos como límites al poder así lo exigía. Lo que en el "common law» podía fiscalizarse, con todos sus riesgos, por la vía de las instrucciones al jurado, en el derecho continental había de controlarse por la vía de la motivación.

Por otro lado, la relación entre presunción de inocencia y motivación probatoria necesariamente exigía una desubjetivización del fenómeno probatorio ${ }^{31}$, pues si son características esenciales de las creencias y convicciones su ocurrencia involuntaria ${ }^{32}$

29 En el «common law», la composición homogénea del Tribunal del jurado puede provocar similares efectos.

30 Véase Tomás Y Valiente, F., 1993: 115 y ss.

31 Igartua SalaVerria, J., 2009: 181: un sujeto puede estar íntimamente convencido de la verdad de una proposición y ser falsa o de la verdad de algo y no disponer de elementos de juicio suficientes para alcanzar tal convicción.

32 Ferrer Beltrán, J., 2003: 85. 
y su independencia respecto del contexto ${ }^{33}$, por lo que se trata de estados subjetivos variables entre personas y también en una misma persona en momentos distintos, no cabe la menor duda de que el control de la corrección del razonamiento probatorio por el tribunal superior o por la comunidad sería imposible, con lo que nunca podríamos estar seguros de tal corrección, lo que violaría, además, el principio de prohibición de la arbitrariedad de los poderes públicos (art. 9.3 CE). En la nueva epistemología de la racionalidad impuesta por la Constitución el foco de atención dejaba de ser el estado mental del juez (inaccesible) y se desplazaba a la presencia de criterios normativos de justificación adecuadamente explicitados, lo que, en su caso, permitía calificar de racional la convicción de aquel. Y tales criterios normativos no podían ser meras intuiciones o impresiones provenientes del cuadro probatorio. Pero tampoco supuestas racionalizaciones de creencias lógicamente erróneas o empíricamente falsas (v.gr., la gestualidad del testigo siempre nos indica la verdad del testimonio).

Lo anterior tuvo reflejo directo en la apreciación probatoria del testimonio único, pues si bien la Lecrim no sufrió modificación alguna a este respecto y, por tanto, no se introdujeron pruebas legales negativas ${ }^{34}$, pronto se tuvo conciencia de la necesidad de explicar, con criterios racionales, los motivos por los que un Tribunal había decidido depositar su confianza en la declaración del testigo para condenar al acusado. Así, la STS 217/2018 (ROJ 1743/2018, ponente Sr. del Moral García) ha acabado señalando que aunque

«...la palabra de un solo testigo puede ser suficiente en abstracto para alcanzar la convicción subjetiva...la exigencia de una fundamentación objetivamente racional de la sentencia hace imposible fundar una condena sobre la base de la mera "creencia" en la palabra del testigo", a modo de un acto de fe ciego, sino que "Se hace imprescindible una valoración de la prueba especialmente profunda respecto de la credibilidad. Cuando una condena se basa en lo esencial en un testimonio ha de redoblarse el esfuerzo de motivación fáctica. Sus exigencias se acrecientan».

A tal efecto, desde finales de los años 80 , el TS había venido fijando los parámetros desde los cuales debía valorarse la «credibilidad» de quienes afirman ser víctimas

33 Igartua Salaverria, J., 2009: 182 «uno puede creer en los días pares del calendario que Madrid sea una ciudad ruidosa y en los días impares no creer tal cosa».

34 Un destacable intento de introducirlas lo encontramos en el Anteproyecto de desarrollo de los derechos fundamentales vinculados al proceso, de 2011 que estableció que la Ley de Enjuiciamiento determinaría los medios de prueba que, por sí solos, fueran objetivamente inidóneos para inferir la culpabilidad del acusado con el suficiente grado de certidumbre; así como en el Anteproyecto de Ley de Enjuiciamiento Criminal, que en los arts. 530.2 y 600.3, imponían el sobreseimiento de la investigación y la absolución, en caso de haberse celebrado juicio, cuando los únicos medios investigativos o pruebas, respectivamente, hubieran sido $a$ ) la declaración de coinvestigados o coacusados; $b$ ) la declaración de testigos de referencia, y c) la mera identificación visual. En tales casos, solo podría avanzar el procedimiento o dictarse sentencia de condena cuando «además de esos elementos probatorios concurran otros que racionalmente corroboren la información que aquéllos proporcionen».

En mi opinión, constituye una opción legislativa plenamente respetuosa con el contenido constitucional de la presunción de inocencia, pues el establecimiento de tales reglas de prueba legal negativa, tiene muy sólidas razones epistémicas, lo que contrasta con el elevado número de sentencias de condena que se dictan en la práctica judicial basados en ellas, en especial en las diligencias de identificación visual por parte de un testigo víctima único y aconsejan, por razones de política judicial, su introducción. 
(por lo general, testigos únicos por excelencia): la «ausencia de incredibilidad subjetiva», la «verosimilitud» y la «persistencia en la incriminación». En suma, desde entonces, y con alguna modificación terminológica en función del ponente, los ítems a valorar han venido siendo los siguientes:

a) La credibilidad subjetiva de la víctima, que se acostumbra a constatar, además de por algunas características físicas o psíquicas singulares del testigo que pudieran debilitar su testimonio (discapacidades sensoriales o psíquicas, edad, etc.), por la concurrencia de móviles espurios, en función de las relaciones anteriores con el sujeto activo (odio, resentimiento, venganza o enemistad), o de otras razones (ánimo de proteger a un tercero o interés de cualquier índole que limite la aptitud de la declaración para generar certidumbre).

b) La verosimilitud del testimonio, ámbito en el que se considera fundamentalmente la coherencia interna del relato o la lógica o plausibilidad de la declaración, y la existencia de datos objetivos periféricos corroboradores, aun cuando no se da el paso a convertir en exigencia la concurrencia de esos datos ${ }^{35}$, y

c) La persistencia en la incriminación, donde se examina la ausencia de modificaciones esenciales en las sucesivas declaraciones del testigo, la concreción en la declaración (sin vaguedades o ambigüedades) y la ausencia de contradicciones entre las distintas declaraciones.

La introducción jurisprudencial de dicho «test» obedeció a la conveniencia de marcar al aplicador una «hoja de ruta» para conjurar el «pensamiento mágico» o decisionista, como un intento para prevenir o limitar la arbitrariedad judicial en la apreciación probatoria. Con todo, un deficiente entendimiento de la función que desempeña este "test» ha dado lugar a que no pocos tribunales estimaran que la concurrencia, en un caso concreto, de los tres parámetros (sin "corroboración periférica») había de traducirse en el otorgamiento al testimonio de la condición de prueba de cargo suficiente para desvirtuar la presunción de inocencia ${ }^{36}$, en una suerte de retorno a la prueba legal positiva. Inversamente, algunos también han entendido, de modo igualmente erróneo, que la ausencia de alguno de esos elementos invalidaba el testimonio. Y ello, pese a ser evidente que se trata de simples pautas para evaluar el grado de credibilidad personal y de sinceridad del testigo (la correspondencia entre lo que afirma y lo que cree sobre lo que afirma), pautas que han de ponderarse con carácter previo a la entrada en el juicio crítico del contenido de la declaración, pero que no pueden sustituir a este ${ }^{37}$.

35 Algunos ponentes del Tribunal (v.gr. L. Varela Castro) empleando una nueva terminología sustituyen el término de verosimilitud por el de credibilidad objetiva, apuntando una línea que parece exigir junto a la vertiente interna (verosimilitud), la externa (corroboración).

36 Véase Andrés IbáÑEz, P., 2009: 121 y ss.

37 Piénsese que un testigo puede ser subjetivamente creíble (por no tener malas relaciones con el acusado), verosímil (en tanto su declaración fuera plausible o conforme a la lógica y a la experiencia) y persistente en sus manifestaciones (por haber mantenido siempre el mismo relato) y aun así, su testimonio no adecuarse a lo verdaderamente acontecido. En sentido inverso, un testigo puede tener malas 


\subsection{La versión racionalista exige la corroboración del testimonio}

\subsubsection{Coherencia y corroboración: de la credibilidad a la frabilidad}

Llegados a este punto, parece obvio que cabe concluir que el "convencimiento personal» de quien enjuicia es insuficiente a los efectos que contempla el art. 24.2 $\mathrm{CE}$, pues la cuestión no es si los medios de prueba practicados persuaden al juzgador acerca de la culpabilidad de la persona acusada, sino si tienen aptitud para convencer a cualquier persona dotada de racionalidad, haya o no asistido al juicio. Dicho en otras palabras: las causas del convencimiento han de ser intersubjetivamente transmisibles, controlables y compartibles. En otro caso, carecen de virtualidad epistémica.

La característica esencial del razonamiento, de la que el probatorio es un subtipo, es su universalidad. Las razones deben servir como justificación para cualquiera que pudiera colocarse en el lugar del juzgador. Por ello, la convicción subjetiva de quien enjuicia jamás puede sustentar por sí sola la condena: si entiende que faltan pruebas para desvirtuar la presunción de inocencia, pese a que en su fuero interno entienda acreditada la hipótesis de la culpabilidad del acusado, necesariamente ha de absolver, sin que sea lícito que acuda a procedimientos que tiendan a sobrevalorar o infravalorar medios de prueba para ajustar la realidad probatoria a la convicción interior. Las certezas subjetivas que pudiera tener el juzgador sobre lo que pudo ocurrir son irrelevantes, pues el plano psicológico, al que pertenece el convencimiento, no siempre coincide con el racional, en el que se enmarca la valoración probatoria como actividad justificada sobre la base de su adecuación a criterios normativos universales y explicitables. En un Estado Constitucional, las partes y el público en general tienen derecho a conocer las razones por las que una persona es o no declarada culpable de un hecho delictivo. $\mathrm{Y}$ esas razones no pueden consistir en la simple convicción personal del juzgador, como vimos antes. Han de ser intersubjetivamente asequibles, lo que solo permite la valoración a través de criterios de racionalidad contrastables y susceptibles de confirmación y refutación.

Así las cosas, sería preferible, por su mayor precisión, sustituir el ambiguo término «credibilidad» del testigo por el de «fiabilidad» del testimonio o, al menos, optar por el de "credibilidad objetiva», que emplean algunos magistrados del Tribunal Supremo.

Especialmente ilustrativa es la STS 18.12.17 (ROJ 4489/2017, ponente Sr. Varela Castro). Dicha resolución recuerda que la garantía de la presunción de inocencia exige someter a crítica la justificación expresada por la sentencia de condena a fin de constatar si la existencia de los medios probatorios permiten razonablemente (por su sentido incriminatorio) afirmar los enunciados de hechos que son declarados probados. A tal fin, señala, la justificación de la conclusión probatoria «ha de establecer los datos de procedencia externa aportados por medios cuya capacidad persuasoria

relaciones con el acusado, o haber variado en algunos extremos su relato, y, no obstante, aportar hechos que se correspondan con la realidad de lo acontecido por encontrar respaldo en otros datos probatorios. 
sea tributaria de la credibilidad del medio de prueba directo y de la verosimilitud de lo informado». En concreto, tratándose de prueba directa (como la testifical) la valoración de la razonabilidad del crédito que se le confiere se encuentra ligada con la percepción inmediata del juzgador que preside la práctica de aquella. Sin embargo, como sigue diciendo la citada resolución, ello

....no releva de la exigencia de que la impresión que así se produce en el receptor no deba revalidarse desde la perspectiva de criterios objetivos. Como tampoco sería admisible fundar la resolución en una especie de acto de fe incondicionado en la veracidad de la versión de quien se dice víctima, por repugnante que sea el hecho denunciado, la vulnerabilidad de aquélla o la frecuencia de este tipo de hechos. En ese sentido, se dice a continuación: "Desde luego, cuando de la declaración testifical se trata no parece que parámetros como persistencia, verosimilitud y ausencia de contradicciones o de motivos espurios en la declaración sean suficientes, ni los únicos atendibles, para satisfacer aquel canon que legitime esa valoración por pretendidamente racional. La justificación constitucional exigible debe ir más allá de las meras impresiones subjetivas sentidas por el receptor de la prueba. Y, desde luego, de las insistencias externas al proceso, por numerosas e incluso comprensibles que puedan ser éstas. La racionalidad de la credibilidad otorgada al testigo, también cuando es la víctima, obliga a exponer las concretas razones por las que se pueden despejar las dudas que podían suscitar la presencia, e incluso la ausencia, de datos, susceptibles de ser alegados en descargo por la defensa del imputado. En particular en relación con el escenario o el objeto o cuerpo de la persona sobre la que recae la acción delictiva, al tiempo o después del hecho, cuando el delito sea de aquellos cuya ejecución es acompañada o seguida habitualmente de vestigios o huellas en aquellos lugares, objetos o cuerpos. Solamente así se podrá controlar si la certeza sobre la veracidad de las afirmaciones de los hechos de que parte la recurrida cumplen o no el canon constitucional implícito en la garantía de presunción de inocencia ${ }^{38}$.

Ciertamente, la sentencia no llega a explicitar lo que en ella subyace: la exigencia de corroboración externa del testimonio, pues tal exigencia no es compartida por todos los miembros del Alto Tribunal, pero lo apunta al referirse a las hipótesis delictivas respecto de hechos «cuya ejecución es acompañada o seguida habitualmente de vestigios o huellas...».

En la misma línea de distinción entre credibilidad subjetiva y fiabilidad, es también destacable la sentencia de la Sección Cuarta de la Audiencia Provincial de Tarragona de 13.6.17 (ponente Sr. Hernández García, ROJ SAP T1155/2017). En síntesis,

Lo fiable de la información hace referencia a las condiciones fenomenológicas de producción probable de lo relatado mientras que lo creíble atiende más a un plano subjetivo, a que el testigo no ha mentido, por lo tanto más abierto a valoraciones y prejuicios de tipo culturalistas e intuitivistas. Lo primero -lo fiable - exige mayores cargas de justificación al juez que atribuye valor a la información. Lo segundo -lo creíble- favorece la utilización de fórmulas de justificación con menores cargas cognitivo-materiales... La fiabilidad, como elemento para otorgar valor reconstructivo a la información suministrada por un testigo, se nutre en muy buena medida del grado de compatibilidad de dicha información con el resultado que arrojan el resto de las pruebas que

38 En la misma línea, cabe reseñar la memorable STS 451/2015, de 14.7.15 (ROJ: STS 3243/2015), dictada por otro de los ponentes (Sr. Andrés Ibáńez) que, junto a los Sres. Varela Castro y Jorge Barreiro, se ha caracterizado por defender en el Tribunal un modelo de valoración racional de la prueba que desconfía del testimonio único, en especial cuando se asocia al paradigma de la «íntima convicción». 
integran el cuadro probatorio plenario y las demás circunstancias contextuales que han quedado acreditadas... Precisamente, la idea de cuadro, la necesidad de atender a un esquema en red de las aportaciones probatorias que se derivan de los diferentes medios plenarios practicados es lo que permite extraer valoraciones materiales y razones justificativas comunicables de tipo cognitivo.

Pues bien, la consecuencia natural de todo lo anterior es que, en los supuestos de testimonios únicos, la clave de bóveda, el elemento central en la valoración probatoria, sea la presencia de elementos externos de corroboración. En suma:

a) Los aspectos personales relativos al testigo, ajenos a la calidad de la información verbal que proporciona, tales como su apariencia física, disposición, gestualidad, seguridad o nerviosismo, que tradicionalmente se han sobrevalorado por un mal entendimiento del principio de inmediación, no solo son equívocos, como enseña la psicología del testimonio, sino que, además, no son controlables intersubjetivamente, por lo que no satisfacen las exigencias motivadoras que impone el art. 24.2 CE.

b) En cuanto a los aspectos relativos al testimonio, suele distinguirse entre coherencia y corroboración. La coherencia alude a la perspectiva interna del relato, y toma en consideración la congruencia de la historia, infiriéndose su credibilidad de la «... existencia de una acción central que resulte fácilmente identificable y se encuentre asociada a un contexto que proporcione una explicación aceptable del comportamiento de los sujetos que en ella intervienen» ${ }^{39}$. La corroboración, por su parte, considera la fiabilidad del testimonio desde una óptica externa, tomando en cuenta los datos objetivos verificables que le prestan apoyo. Así las cosas, aunque coherencia y corroboración son controlables en la motivación probatoria, en los supuestos de testimonio único la coherencia del relato no colma los requerimientos que impone la presunción de inocencia, pues si los elementos informativos de contexto que permiten calificar de coherente el relato provienen de la misma fuente de prueba cuya fiabilidad se pretende calibrar, no habría manera de controlar la posible falsedad de dicho relato, por lo que, en puridad, acabaríamos recurriendo a un juicio subjetivo de credibilidad sobre la persona del testigo.

c) En esa línea, ha de recordarse que la finalidad de la valoración individualizada de cada medio de prueba no es coincidente con la de la valoración conjunta ${ }^{40}$. La primera persigue testar la confiabilidad singular, la atendibilidad de cada medio de prueba. La segunda, evaluar el grado de confirmación que la hipótesis acusatoria recibe de las pruebas calificadas de atendibles. En los supuestos de pluralidad de medios, la atendibilidad individual de cada uno de ellos nada indica todavía sobre su peso probatorio respectivo. Sin embargo, en los supuestos de testimonio único, por lo general, de la calificación del medio como fiable se inferirá la prosperabilidad de la tesis acusatoria. Si esto es así, se hace imprescindible exigir una corroboración

39 López Ortega, JJ., 2018: 3 y ss. Integro así en un solo concepto los aspectos que Nieva Fenoll, J., 2010: 223 y ss, desdobla en coherencia estricta (en el sentido de estructuración lógica) y contextualización (aportación de datos descriptivos del ambiente vital, espacial o temporal en que los hechos tuvieron lugar).

40 Véase Igartua Salaverría, J., 2009: 167 y ss. 
al testimonio, pues en los casos de pluralidad de pruebas existe un potente mecanismo de control de la fiabilidad de cada medio que no está presente en los supuestos de prueba única. Hay dos aproximaciones posibles. Conforme a la primera, en la valoración individualizada del medio a testar puede contrastarse la información que proporciona el testigo con las informaciones que provienen de otras fuentes de prueba y, en caso de disparidad absoluta, calificar de no atendible el medio cuestionado. Conforme a la segunda, la valoración individualizada del medio no exigiría superar un estándar tan riguroso, bastando una narración proveniente de un testigo sin tachas personales que proporciona una información coherente. Ahora bien, en la valoración conjunta tal información sería sometida a contraste con el resto de informaciones procedentes de otros medios de prueba, operación que permitiría fijar pesos probatorios. De uno u otro modo, ya optemos por una u otra aproximación, se observa que el «juicio de fiabilidad» individual está íntimamente conectado con la valoración conjunta. Aunque sean operaciones que, por razones didácticas o metodológicas, conviene distinguir, en la práctica (dejando a un lado los casos groseros de testigos evidente y absolutamente mendaces) no son exactamente secuenciales, sino que interactúan en relación de circularidad. Ello no es posible, por definición, en los supuestos de testimonio no corroborado, pues la hipótesis acusatoria se habría construido sobre la exclusiva base del mismo, por lo que todo lo que en ella se contuviera solo dispondría de su propio aval.

En definitiva, cuando un juez decide sobre la hipótesis acusatoria a la vista de un solo testigo no corroborado, nunca sabremos si condenó deliberadamente de forma injusta. Pero tampoco, si se equivocó, dadas las particularidades de la prueba testimonial. Como enseñan destacados referentes de la psicología del testimonio ${ }^{41}$, en la codificación de la información que el testigo recibe no solo influye la corrección de la percepción (que puede ser errónea), sino también los conocimientos previos del testigo, pues al tiempo que percibimos un suceso lo estamos interpretando, de modo que lo que se almacena en la memoria no solo se basa en la pura percepción sensorial, sino en el trasfondo cultural de quien percibió el hecho y en las inferencias probables que realizó sobre aspectos no percibidos, basadas en esos conocimientos previos. Por otra parte, la falta de correspondencia entre el testimonio y la realidad no encuentra causa principal solo en la mentira, sino también en otros factores tales como el olvido, que opera cuantitativa y cualitativamente (olvidamos más datos y más selectivamente, por lo que el recuerdo tiende a hacerse «redondo») y la sugestión, que puede suprimir la memoria real e inducir recuerdos falsos, aun de forma involuntaria, por malas prácticas de los investigadores que protagonizan los interrogatorios en función del contenido y forma de las preguntas que realicen ${ }^{42}$. Y, comoquiera que una vez construido el recuerdo es prácticamente imposible distinguir si es verdadero o fal-

41 Sigo en este punto a Diges, M., 2016 y a Mazzoni, G., 2010.

42 Dejamos a un lado, por razones de espacio, otros factores a considerar y generalmente concurrentes en el momento de adquisición o codificación de la información, así como otros presentes en las fases de retención y en la de recuperación. 
so ${ }^{43}$, o imponemos garantías epistemológicas adicionales, como las corroboraciones, o aceptamos la multiplicación de las posibilidades de condenas de falsos culpables.

Por último, conviene apuntar que en las declaraciones incriminatorias de los coacusados el TS siempre ha exigido la existencia de corroboraciones, aun cuando fueran mínimas, sobre la base del argumento de que, por la condición procesal que ocupan aquéllos, realizan declaraciones «intrínsecamente sospechosas», pues los acusados no tienen la obligación de decir la verdad, y sus manifestaciones pueden venir guiadas por móviles espurios tales como la autoexculpación o la presencia de pactos con la acusación, lo que justifica una mayor exigencia acreditativa, que no se requiere en el caso de las declaraciones testificales. Sin embargo, no encuentro razones de peso que justifiquen un distinto tratamiento probatorio, pues el hecho de que el testigo venga obligado a decir la verdad no significa que sea veraz. Del mismo modo, ni todos los acusados declaran impulsados por un móvil espurio, ni en todos los testigos están ausentes esos móviles ${ }^{44}$. Y unos y otros están expuestos a sus prejuicios culturales, a la mentira, el olvido y la sugestión. Cuestión distinta es qué deba entenderse por circunstancias corroboradoras.

\subsubsection{Las circunstancias corroboradoras}

Tal y como sucede, por lo general, en los sistemas procesales continentales, en el proceso penal inglés el acusado puede ser condenado sobre la base de un testimonio único, sin la presencia de corroboraciones ${ }^{45}$. Con anterioridad a la vigencia del Criminal Justice Act de 1988 y del Criminal Justice and Public Order Act, de 1994, el common law venía exigiendo que el juez advirtiera a los miembros del jurado de los riesgos de declarar probada la culpabilidad sobre la base de cierta clase de testimonios no corroborados; en concreto, los de los menores de edad, las víctimas de delitos sexuales y los copartícipes. Tales advertencias han dejado legalmente de requerirse ${ }^{46}$. No obstante, se mantienen en leyes específicas, como la Road Traffic Regulation Act de 1984, previsión que parece epistemológicamente lógica ${ }^{47}$, y también parecen haberse extendido a todos aquellos casos en los que exista base para sospechar de la fiabilidad del testigo ${ }^{48}$.

43 A ello nos referiremos más adelante al abordar las particularidades de las pruebas periciales sobre fiabilidad de los testimonios.

44 Así, v.gr, frente a la afirmación de que el acusado tendría interés en lograr su exculpación, puede objetarse que la víctima tiene interés en la condena de aquel.

45 Sigo a Roberts, P. y Zuckerman, A., 2004: 465 y ss.

46 Es patente la presencia de un estereotipo de género al imponerse preceptivamente la instrucción sobre la necesidad de corroboración respecto de las víctimas de delitos sexuales (generalmente mujeres) y no respecto de las víctimas. de otros muchos delitos

47 Section 89(2): "A person prosecuted for a speeding offence shall not be liable to be convicted solely on the evidence of one witness to the effect that, in the opinion of the witness, the person prosecuted was driving the vehicle at a speed exceeding a specified limit».

48 R. vs. Makanjuola, 1995. 
Roberts y Zuckerman ${ }^{49}$ cuestionan los sistemas legales en los que los testimonios no corroborados no permiten la declaración de culpabilidad, sobre la base del riesgo de la impunidad de los delitos clandestinos. Con todo, también advierten que en los ordenamientos donde la corroboración se exige, lo que se produce es una rebaja de los requisitos que han de concurrir para que puede hablarse de corroboración. En otros términos: se parte de un concepto muy amplio de la misma. Así, mientras que, conforme al common law, la corroboración debe provenir de una fuente de prueba ajena al testigo, y vincular al acusado con el delito, confirmando la existencia del ilícito y la participación del acusado en él ${ }^{50}$, en la práctica del proceso penal escocés, en algún caso ha bastado para entenderla concurrente que la declaración del acusado ${ }^{51}$ cuando confiesa los hechos evidenciara un especial conocimiento de la existencia de otras pruebas del delito.

Pese a lo señalado, no está de más recordar que el Tribunal Europeo de Derechos Humanos (en lo sucesivo, TEDH), cuando se ha enfrentado a supuestos de condenas de Tribunales británicos basadas en testimonios únicos referenciales, referidos o no comparecidos, ha exigido como presupuesto de compatibilidad de la decisión del jurado (inmotivada) con los mandatos de motivación y contradicción que impone el art. 6 del Convenio Europeo de Derechos Humanos (en lo sucesivo, CEDH), ciertos estándares de calidad a las instrucciones valorativas que ha de proporcionar el juez que preside el jurado a los miembros que lo componen. Así, desde Al-Khawaja y Tahery c. Reino Unido (STEDH Gran Sala 15.12.2011) se ha asentado el criterio de que en supuestos de condenas basadas, únicamente o de modo decisivo, en tales testimonios, no siempre habrá vulneración del derecho a un proceso equitativo si en el caso concreto existen «suficientes factores de compensación, incluyendo medidas que permitan una correcta y adecuada evaluación de la fiabilidad de esa prueba. Esto permitiría que una condena se fundara únicamente en dicha prueba solamente si es suficientemente fiable dada su relevancia en el caso». ( $\$ 147)$. Ello implica, entre otras cosas, que las instrucciones hagan especial hincapié en los riesgos de la inexistencia de confirmaciones y corroboraciones, lo que pone de relieve la importancia de lo objetivo y externo como piedra de toque de la valoración.

En cuanto a nuestro derecho, no existe norma legal positiva que defina la corroboración, ni encontramos en la jurisprudencia del TC ni en la del TS una conceptuación precisa de la misma, posiblemente para dejar cierto margen de apreciación en casos concretos ${ }^{52}$.

El TC ha abordado el fenómeno de las corroboraciones al tratar las declaraciones de los coacusados. Sin embargo, el cotejo de su doctrina impide una reconstrucción precisa de lo que deba entenderse por tal. Así, encontramos pronunciamientos que

\footnotetext{
49 Roberts, P. y Zuckerman, A., 2004: 467.

50 Desde R. vs. Baskerville, 1916.

51 Quien introduce información probatoria en el proceso como testigo cuando decide declarar.

52 El Anteproyecto de Ley de Enjuiciamiento Criminal de 2011, aunque se refiere a la necesidad de las corroboraciones en ciertos casos no llega a definirlas.
} 
parecen contradictorios como los siguientes: «La corroboración mínima resulta exigible no en cualquier punto, sino en relación con la participación del recurrente en los hechos punibles que el órgano judicial considera probados» (STC 125/2009, de 18 de mayo), pero también «La corroboración externa mínima y suficiente no constituye una prueba, pues, en otro caso, bastaría ésta sin necesidad de las declaraciones de los coimputados, la corroboración es la confirmación de otra prueba, que es la que por sí sola no podría servir para la destrucción de la presunción de inocencia, pero que con dicha corroboración adquiere fuerza para fundar la condena» (STC 198/2006, de 3 de julio). Más claro ha sido al definir negativamente la corroboración. En suma, la declaración de un coacusado no constituye corroboración mínima de la de otro coacusado (STC 72/2001, de 26 de marzo), ni los factores de credibilidad objetiva de la declaración, tales como la persistencia en la incriminación, la ausencia de incredulidad subjetiva, ni la coherencia en el relato (STC 134/2009, de 1 de junio).

En cuanto al TS, y centrándonos en las declaraciones testificales de las víctimas, tiene establecido lo siguiente (por todas, STS 544/2016 (ROJ: STS 3044/2016):

La declaración de la víctima ha de estar rodeada de corroboraciones periféricas de carácter objetivo obrantes en el proceso; lo que significa que el propio hecho de la existencia del delito esté apoyado en algún dato añadido a la pura manifestación subjetiva de la víctima (Sentencias de 5 de junio de 1992; 11 de octubre de 1995; 17 de abril y 13 de mayo de 1996; y 29 de diciembre de 1997). Exigencia que, sin embargo, habrá de ponderarse adecuadamente en delitos que no dejan huellas o vestigios materiales de su perpetración (art. 330 LECrim), puesto que, como señala la sentencia de 12 de julio de 1996, el hecho de que en ocasiones el dato corroborante no pueda ser contrastado no desvirtúa el testimonio si la imposibilidad de la comprobación se justifica en virtud de las circunstancias concurrentes en el hecho. Los datos objetivos de corroboración pueden ser muy diversos: lesiones en delitos que ordinariamente las producen; manifestaciones de otras personas sobre hechos o datos que sin ser propiamente el hecho delictivo atañen a algún aspecto fáctico cuya comprobación contribuya a la verosimilitud del testimonio de la víctima; periciales sobre extremos o aspectos de igual valor corroborante; etcétera.

Como puede observarse, aun cuando de la afirmación inicial (el propio hecho de la existencia del delito debe estar apoyado en algún dato ańadido a la pura manifestación subjetiva de la víctima), se desprende que se opta por un sentido fuerte de la corroboración cuando sea precisa (no se cierra la posibilidad de que el testimonio no corroborado sea suficiente cuando no existan vestigios del hecho ${ }^{53}$ ), también hay base para entender que se admite la corroboración en sentido débil («datos que sin ser propiamente el hecho delictivo atañen a algún aspecto fáctico cuya comprobación contribuya a la verosimilitud del testimonio de la víctima»).

53 Lo que parece contradictorio con las afirmaciones contenidas en la Sentencia del Tribunal Supremo 734/2015 (ROJ STS 5082/2015, ponente Sr. Del Moral García), que apunta a que el argumento nos retrotraería a los llamados delicta excepta, y a la inasumible máxima «In atrocissimis leviores conjecturae sufficiunt, et licet iudice iura transgredi» (en los casos en que un hecho, si es que hubiera sido cometido, no habría dejado «ninguna prueba», la menor conjetura basta para penar al acusado). 
En este contexto de cierta indefinición, me parecen especialmente valiosas las observaciones de ANDRÉs IBÁŃEZ ${ }^{54}$. En opinión del autor, corroborar es reforzar el valor probatorio de la afirmación de un testigo relativa al hecho principal de la causa, mediante la aportación de datos de una fuente distinta, referidos no directamente al hecho principal, sino a alguna circunstancia que guarda relación con él, cuya constatación confirmaría la veracidad de lo declarado por el testigo. De la anterior definición se desprenden las siguientes notas:

a) El objeto de la corroboración es un enunciado fáctico emitido por el testigo sobre el hecho principal. No, por tanto, directamente enunciados sobre el hecho principal, ni tampoco enunciados sobre hechos secundarios.

b) La fuente de la corroboración ha de ser ajena al testigo. El dato corroborador debe provenir, por tanto, de otro lugar.

c) El contenido informativo del dato corroborador no versa directamente sobre el hecho principal, sino sobre alguna circunstancia que guarda relación con él, y cuya constatación reforzaría la veracidad de lo declarado por el testigo.

En suma, como indica aquel, «Corroborar es probar, pero no directamente la acción que da contenido a la imputación, sino un hecho relacionado con ella y con el inculpado, cuya producción en determinadas circunstancias abonaría en términos de la experiencia la certeza de que, en efecto, la misma ha tenido lugar con intervención de aquél».

Pues bien, concebida la corroboración en dichos términos, es evidente que su exigencia introduce un conveniente elemento de prevención de la arbitrariedad o del error judicial en la apreciación de las pruebas al anclar esta última en el terreno de lo objetivable y, por tanto, controlable. Dicho en otros términos, sólo mediando su presencia es viable una mínima justificación racional de la valoración probatoria, pues someteríamos a contraste lo que el testigo dijo con un elemento que confirmaría o infirmaría lo que manifestó como paso previo a declarar o no probada la hipótesis acusatoria. Pero, además, la exigencia de respaldo, en tales términos, tampoco constituye necesariamente un muro infranqueable que impida la sanción penal de los delitos cometidos en la clandestinidad, sirviendo, por el contrario, de estímulo al investigador para buscarlas.

En resumen: el testimonio único, sea el de la víctima, sea el de un tercero, en sentido estricto (no corroborado) es prueba insuficiente para acreditar la hipótesis acusatoria como paso previo a la condena. La declaración de un solo testigo solo es apta a tal efecto si algunos de los datos probatorios relevantes que de ella resulten encuentran respaldo en otras fuentes de prueba. Ello, como es obvio, no exime al juzgador de la obligación de hacer un juicio crítico del dato corroborante. Pero, además, indica al investigador el camino que ha de transitar si quiere asegurar el éxito del juicio oral: obtener de la declaración de la víctima todos los datos relevantes para buscarles respaldo en otras fuentes de prueba.

54 ANDrés IbáÑEZ, P., 2009: 124 y ss. 


\section{EL TESTIMONIO ÚNICO ANTE LA VIOLENCIA DE GÉNERO: NUEVOS EQUÍVOCOS 55}

Por lo que nos interesa ahora, la perspectiva de género exige que el relato que realiza la mujer que narra haber sido víctima de actos violentos protagonizados por el hombre se evalúe eliminando estereotipos que tratan de universalizar como criterios de racionalidad simples máximas de experiencia machistas (v.gr.: el estereotipo de "víctima ideal» que, tras sufrir el hecho, lo denuncia inmediatamente, mantiene siempre un relato idéntico de lo acontecido y se aísla socialmente; el estereotipo de mujer sexualmente disponible para cualquier hombre, inducido de datos con pretendido valor indiciario tales como su vestimenta, su estado de embriaguez o el lugar y hora de la noche en la que se le encuentra y, frente a él, el de la mujer decente; o los estereotipos de la buena esposa o buena madre).

Pues bien, sobre esa base, se ha venido a defender la virtualidad como prueba de cargo del testimonio único no corroborado de quien afirma ser víctima de un delito que quepa categorizar como violencia de género ${ }^{56}$. Estos delitos se caracterizarían por la presencia de dos bienes jurídicos ${ }^{57}$, el personal de la víctima y el colectivo, conformado por el hecho de la pertenencia de la mujer al género femenino, que sería abstractamente agredido y, por tanto, siempre sujeto pasivo mediato en todos los delitos del grupo. De ahí la relevancia de utilizar la perspectiva de género como herramienta valorativa, como elemento auxiliar de evaluación de la prueba que serviría, para los defensores de estas tesis, en el supuesto límite de la escasez probatoria (el testimonio no corroborado), para avalar la hipótesis de la acusación.

En apoyo de tal posibilidad probatoria, se han aportado distintos argumentos. Los examinaré seguidamente, y expondrá mis objeciones a continuación.

\subsection{El riesgo de impunidad}

Son distinguibles dos perspectivas:

a) Según se afirma, se trata de delitos que plantean especiales dificultades probatorias al cometerse habitualmente en la privacidad, por lo que, en principio, la única prueba directa que existe es el testimonio de la víctima, de modo que, de no aceptarse dicho testimonio como única prueba de cargo, se llegaría a la más absoluta impunidad en la mayor parte de los casos.

55 Utilizo la denominación de «violencia de género» en sentido amplio, y no en el reducido del Código Penal español en el que solo se consideran supuestos de violencia de género determinados delitos cometidos por el hombre sobre la mujer pareja.

56 Entendida en sentido amplio, y no restringida a la violencia cometida por el hombre sobre la mujer pareja o ex pareja.

57 Aunque la cuestión no es pacífica en la doctrina penal. 
Frente a la perspectiva enunciada, no exenta de riesgos, pues puede llevar a sobrevalorar un testimonio insuficiente, estimo más correcta otra aproximación: razones epistemológicas y político-institucionales aconsejan recelar del testimonio único no corroborado para fundar una sentencia de condena. En cuanto a las primeras, nos remitimos a lo expuesto anteriormente, añadiendo las altísimas tasas de error a que conducen los simples juicios subjetivos de credibilidad. En cuanto a las segundas, es preciso recordar que las instituciones que participan en el sistema de control penal se condicionan recíprocamente. Cuantos menores sean los niveles de exigencia probatoria aceptados por los tribunales, menores serán los esfuerzos investigativos y acreditativos realizados por los cuerpos policiales y los órganos de la investigación y acusación. Por el contrario, mayores niveles de exigencia estimulan mejores investigaciones y acopio de pruebas de distinto origen. Por otra parte, las resoluciones de condena que no toman en consideración elementos corroboradores al no ser intersubjetivamente compartibles no pueden ser racionalmente controladas a través del sistema de recursos. Por último, un sistema que permite que las condenas se basen en testimonios únicos no corroborados compromete seriamente la presunción de inocencia. Y es que no es fácil argumentar sobre la base de qué razones podemos afirmar, en este particular contexto probatorio, que debemos creernos más al testigo que al acusado, quien, igualmente, podría ser subjetivamente creíble, verosímil y persistente en sus manifestaciones u optar, legítimamente, por guardar silencio, sin que fuera legítimo extraer consecuencias negativas del ejercicio del derecho fundamental que le otorga el art. 24.2 CE.

Nieva FenOlL ${ }^{58}$ introduce una matización y señala que si la víctima no presenció los hechos, si no existen corroboraciones de su testimonio la presunción de inocencia exige la absolución. Ahora bien, si los hubiera visto, la sola ausencia de corroboraciones no debiera justificar la absolución, pues ello dejaría en la impunidad la mayor parte de delitos de agresiones sexuales, lesiones y robos. A su entender, en estos casos, lo procedente sería recabar un dictamen pericial de un psicólogo del testimonio a fin de que ilustrara al tribunal sobre la existencia de elementos de credibilidad en la víctima. Creo que no hay razones de peso para distinguir entre el caso del testigo presencial y el no presencial, pues uno y otro, cuando no existen corroboraciones, se enfrentan a la misma objeción expuesta en 3.3.1 c): en suma, la ausencia de referentes externos remite a un mero juicio de credibilidad subjetiva, por lo que, en mi opinión, siguen siendo válidos los argumentos que objetan el riesgo de impunidad. Por otro lado, como desarrollaré más adelante, las pericias psicológicas sobre la credibilidad de los testimonios han de ser sometidas también a un juicio especialmente crítico, y no permiten suplir la ausencia de elementos de corroboración.

b) Se aduce también la especial trascendencia de los delitos de violencia de género, en tanto que, más allá del daño que causan a quienes individualmente los padecen, constituyen el modo más brutal de perpetuar la situación de discriminación que las mujeres sufren.

58 Nieva Fenoll, J., 2010: 249-250. 
Tal argumento es merecedor de idéntica objeción a la anteriormente realizada. Por otro lado, no está de más recordar que el dilema «eficacia vs. garantías» es un falso dilema, pues la función del proceso penal es doble: asegurar el castigo del culpable al tiempo que la protección del inocente, de modo que la satisfacción de todos los intereses en juego (acusados/víctimas/sociedad) solo puede producirse en el marco del proceso debido. Al menos, mientras seamos capaces de seguir sosteniendo como el único legítimo el paradigma de racionalidad propio del derecho penal vigente en los Estados constitucionales.

Por ello, tanto la normativa sustantiva y procesal como su aplicación judicial no pueden perder nunca de vista los principios limitadores de la intervención penal. Entre otras razones, para prevenir la existencia de abusos y errores provenientes de los sujetos institucionales que tienen encomendada la persecución penal, garantizando la existencia de un estándar de prueba exigente y objetivo, la imparcialidad de los decisores en quienes no han de pesar consideraciones político criminales en el momento de la valoración probatoria (distinto es el papel de los investigadores al tiempo de la búsqueda y aporte de pruebas), y el derecho de defensa, que se vería notablemente dificultado de aceptarse un estándar subjetivo de prueba a la vista de una declaración testifical no corroborada.

\subsection{La sobrevaloración de la presunción de inocencia}

En ocasiones, se sostiene que el principio de presunción de inocencia está hipertrofiado, que, en definitiva, no deja de ser un derecho fundamental que, como todos, no es absoluto y, en consecuencia, susceptible de sujeción a ponderación cuando entre en conflicto con otros intereses relevantes. Entre dichos intereses, últimamente se vienen destacando la indemnidad sexual de los menores de edad y la integridad corporal, la libertad y libertad sexual de las mujeres frente a las agresiones de los hombres.

Como es sabido, la presunción de inocencia es un derecho fundamental con diversas vertientes. Una de ellas es doctrinalmente discutida ${ }^{59}$ (en caso de diversidad hermenéutica sobre el alcance de la disposición penal desfavorable ha de optarse por el entendimiento de la misma más favorable para el encausado). Pero las otras dos son de generalizada aceptación.

Como regla de tratamiento impone a las autoridades encargadas de la persecución y enjuiciamiento la obligación de tratar al encausado como si fuera inocente, proscribiendo el dictado de resoluciones que supongan una anticipación de pena o

59 Aun cuando parece encontrar respaldo en la STC 109/1986, de 24 de septiembre y en el argumento de que es contrario al derecho que consagra el artículo 24.2 CE castigar el delito cunado no se tiene la seguridad de lo que el sujeto hizo es justamente lo que la ley define como delito. 
tratamientos informativos que impliquen un prejuicio sobre la culpabilidad ${ }^{60}$. Pero además, la presunción de inocencia es una regla de juicio ${ }^{61}$, que se desdobla en una regla probatoria, que exige para la condena la existencia de actividad probatoria de cargo (suficiente) practicada con todas las garantías, y en un estándar probatorio, o criterio que indica cuándo se entiende acreditada la hipótesis acusatoria. Si la función primordial del proceso es la reconstrucción del pasado conforme a reglas, tal reconstrucción solo puede convertirse en hecho probado si a partir de dichas reglas, bajo las condiciones del discurso racional, puede resistir todos los intentos de refutación. La presunción de inocencia fija el estándar probatorio: la hipótesis de la acusación sólo quedará justificada cuando encuentre respaldo acreditativo más allá de toda duda razonable. Ello, como señala FERrer BeLTrán ${ }^{62}$ implica que: «a) La hipótesis sea capaz de explicar todos los datos disponibles integrándolos de forma coherente; y, b) No han de ser posibles hipótesis más favorables compatibles con los datos disponibles».

Pues bien, si lo que se quiere afirmar es que en determinados tipos delictivos, por los intereses en juego o la dificultad de su descubrimiento, debe sustituirse este estándar por otro menos exigente, como la probabilidad prevalente, tal argumentación no nos remitiría a un juicio de ponderación entre el interés público en la averiguación de la verdad en el proceso y el interés en reconocer la eficacia de los derechos fundamentales y, en concreto, del derecho que reconoce el art. 24.2 CE, sino simple y llanamente ante un abandono de la presunción de inocencia como estándar probatorio. No cabe «rebajar» las exigencias del estándar sin desnaturalizar el derecho fundamental. Lo resultante sería otra cosa, lo que ha llevarnos a preguntarnos por el sentido del derecho.

A juicio de VIVEs AnTón ${ }^{63}$ la contraposición entre presunción de inocencia y verdad es una falacia. Cuando se propone optar por un estándar menos exigente, lo que se propone, en otros términos, es renunciar a la verdad, imponiendo la pena cuando no podemos estar seguros de que el sujeto haya cometido el delito y, en consecuencia, asumir el castigo de los inocentes. No cabe duda, a juicio del citado autor, de que con ello se reforzaría el poder del Estado, pero del mismo modo se debilitaría la dignidad de los ciudadanos.

En mi opinión, el acento debe ponerse en el dato de que el proceso penal no es un instrumento al servicio de la investigación desinteresada de la verdad. La verdad interesa a los solos efectos de ejercitar el ius puniendi, potestad estatal que, por sus efectos sobre la vida de los ciudadanos, se encuentra sujeta a precisos límites que la Constitución y las leyes establecen, entre los que destacan los que representan

${ }^{60}$ En este sentido, revista especial interés la Directiva (UE) 2016/343 del Parlamento Europeo y del Consejo, de 9 de marzo de 2016, por la que se refuerzan en el proceso penal determinados aspectos de la presunción de inocencia y el derecho a estar presente en el juicio.

${ }_{61}$ Esta vertiente no es ajena a la cultura anglosajona. Véase Taylor vs. Kentucky, 436 US. 478, 98 (1978) que cuestiona la tradicional separación entre la presunción de inocencia y el principio de que la acusación tiene la carga de probar más allá de una duda razonable.

62 Ferrer Beltrán, J., 2007: 147 y ss.

63 Vives Antón, T., 2011: 962 y ss. 
los derechos fundamentales. Una hipotética verdad adquirida fuera de esos límites nunca podría legitimar el ejercicio de esa potestad. El dilema no debería, por tanto, plantearse en los ambiguos términos de verdad/garantías (presunción de inocencia) sino de legitimidad/ilegitimidad de la intervención penal. Un estándar que permite resolver la situación de incertidumbre condenando a la persona acusada sería, desde esta perspectiva, ilegítimo ${ }^{64}$.

Además, no debe olvidarse que las reglas procesales y probatorias se dictan y aprueban con pretensión de generalidad, para ser aplicadas a un elevado volumen de asuntos en el que intervendrán un no menos elevado número de jueces, fiscales y policías. Una visión no idealizada de la realidad pasa por aceptar que no puede partirse a priori de que todos los partícipes vayan a estar en posesión de óptimas capacidades sintéticas y valorativas y a actuar guiados por las mejores intenciones. Por ello, es epistemológicamente correcto fijar un estándar probatorio muy exigente como mecanismo de prevención de los riesgos de abuso y de error (siempre presentes cuando el Estado que quiere penar reconstruye el pasado histórico y pretende establecer como verdad el resultado de su propia reconstrucción).

No me parecen, por ello, adecuadas, ciertas recomendaciones impulsadas desde los Consejos de la Judicatura de distintos Estados que dan a entender que en los delitos basados en el género la lucha contra su impunidad resulta aconsejable la «flexibilización de la carga probatoria». Así sucede en la Guía para la Administración de Justicia con perspectiva de género del Consejo de la Judicatura de Ecuador de 2018, que contiene un epígrafe titulado «Flexibilizar la carga probatoria en las infracciones basadas en género", y cita jurisprudencia de la Corte Interamericana de Derechos Humanos en favor de tal flexibilización. La guía dice:
...considerando que una de las características de los delitos sexuales, es que generalmente son perpetrados de manera escondida, sin testigos que puedan confirmar las declaraciones de la víc- tima, la Corte Interamericana ha manifestado que el testimonio debe ser considerado como una "prueba fundamental, y debe ser apreciado dentro del conjunto de las pruebas obtenidas». Igualmente, advierte: «Por su parte, la Corte Interamericana de Derechos Humanos ha emitido diversas opiniones respecto a la valoración de la prueba, señalando que la falta de la realización de exámenes médicos que debe disponer el Estado, no puede cuestionar la veracidad de las de- claraciones de las víctimas. Esto debe ser considerado especialmente en los casos de agresiones sexuales debido a que estos hechos de violencia no siempre implican lesiones físicas evidentes».

Difícilmente puede discreparse de los asertos: a) En los delitos sexuales, el testimonio de la víctima debe ser considerada una prueba fundamental; $b$ ) Dicha prueba ha de valorarse en conjunto con el resto de pruebas; $c$ ) La falta de evidencia clínica de la agresión sexual no denota necesariamente la inveracidad del testimonio. Pero, del mismo modo, de ellos no se deduce la necesidad de rebajar el estándar probatorio. Es posible, por tanto, que lo que este tipo de protocolos y guías pretendan sea tan solo concienciar a aplicadores poco sensibles sobre la necesidad de valorar sin prejuicios los testimonios de quienes afirman ser víctimas de violencia de género y, especial-

\footnotetext{
${ }^{64}$ Ramírez Ortiz, J. L., 2014.
} 
mente, sexual. Y tal pretensión es merecedora de elogio. Pero ello no debe llevar a confundir planos de modo que acabe oscureciéndose la identificación del estándar probatorio exigido. Un estándar, tan inseparable de la configuración del proceso penal de los Estados constitucionales, que permite calificarlo de proceso penal de la presunción de inocencia frente al proceso penal de la sospecha de tiempos, aún más oscuros, que ya creíamos superados.

\subsection{Las diferentes posiciones procesales de quien afirma ser víctima y acusado}

Quien afirma ser víctima y acusado se encuentran en situaciones jurídicas diferenciadas. Así, mientras que la primera, como testigo, tiene obligación de comparecer y de decir la verdad y responder a los interrogatorios, el segundo no tiene obligación de declarar, su silencio no le perjudica y si miente su conducta es impune. En consecuencia, su distinto régimen jurídico ha de encontrar una traducción probatoria, atribuyendo, al menos tendencialmente, mayor valor a la declaración de la víctima.

El argumento no es sostenible por varias razones. Incurre, en primer lugar, en falacia normativista, al inferir el ser del deber ser: que los testigos tengan la obligación de decir la verdad no significa que no mientan. En segundo lugar, devalúa el estatuto de la persona acusada, quien se vería perjudicada siempre y en todo caso por el solo hecho de no prestar declaración bajo juramento. Pero, además, no explicaría cómo afrontar, no contradictoriamente con los postulados de la perspectiva de género, los supuestos en los que la persona acusada fuera mujer y quien afirma ser víctima, un hombre.

\subsection{La atribución a la víctima de la condición de testigo especialmente cualificado}

Resultan de interés, en este sentido, dos sentencias del Tribunal Supremo (Roj: STS 2003/2018, de 24 de mayo y Roj: STS 2182/2018, de 13 de junio; en ambos casos, ponente Sr. Magro Servet), que vienen a sostener que la «víctima» es un testigo privilegiado o cualificado en la medida en que ha sufrido y presenciado el hecho.

«....En estos casos, la víctima se encuentra procesalmente en la situación de testigo, pero a diferencia del resto de testigos, es víctima y ello debería tener un cierto reflejo diferenciador desde el punto de vista de los medios de prueba, ya que la introducción de la posición de la víctima en la categoría de mero testigo desnaturaliza la verdadera posición en el proceso penal de la víctima, que no es tan solo quien "ha visto" un hecho y puede testificar sobre él, sino que lo es quien es el sujeto pasivo del delito y en su categorización probatoria está en un grado mayor que el mero testigo ajeno y externo al hecho, como mero perceptor visual de lo que ha ocurrido"... "Y esto es relevante cuando estamos tratando de la declaración de la víctima en el proceso penal, y, sobre todo, en casos de crímenes de género en los que las víctimas se enfrentan a un episodio realmente dramático, cual es comprobar que su pareja, o ex pareja, como aquí ocurre, toma la decisión de acabar con su vida, por lo que la versión que puede ofrecer del episodio vivido es de gran relevancia, pero no como mero testigo visual, sino como un testigo privilegiado, cuya declaración 
es valorada por el Tribunal bajo los principios ya expuestos en orden a apreciar su credibilidad, persistencia y verosimilitud de la versión que ofrece en las distintas fases en las que ha expuesto cómo ocurrieron unos hechos que, en casos como el que aquí consta en los hechos probados, se le quedan grabados a la víctima en su visualización de una escena de una gravedad tal, en la que la víctima es consciente de que la verdadera intención del agresor, que es su pareja, o ex pareja, ha tomado la decisión de acabar con su vida»... «...se trata de llevar a cabo la valoración de la declaración de la víctima, sujeto pasivo de un delito, en una posición cualificada como testigo que no solo "ha visto" un hecho, sino que "lo ha sufrido", para lo cual el Tribunal valorará su declaración a la hora de percibir cómo cuenta el suceso vivido en primera persona, sus gestos, sus respuestas y su firmeza a la hora de atender el interrogatorio en el plenario con respecto a su posición como un testigo cualificado que es, al mismo tiempo, la víctima del delito».

Creo que la conclusión es difícilmente compatible con el art. 24.2 CE pues en sentido probatorio no hay, no puede haber, víctima antes de la sentencia, del mismo modo que no hay autor antes de ese momento. Con ello no se cuestionan las consideraciones de tipo asistencial ni las prestaciones exigibles a la Administración, que deben poner a disposición de quienes se afirma que han sido víctimas de un hecho delictivo grave todo el apoyo personal y material posible, con independencia de la existencia o inexistencia de la sentencia de condena y concurriendo determinadas circunstancias. Lo que se afirma es que en el marco del proceso el acusado tiene derecho a cuestionar no sólo su participación, sino también la misma existencia del hecho y, por tanto, la invocada condición de "víctima", que no precede al proceso, sino que es, en su caso, su consecuencia, lo que impide otorgar a esta última la pretendida condición de testigo cualificado.

\subsection{La suficiencia de la coherencia del relato}

Está extendida la idea de que, en ciertos casos y especialmente en los delitos de violencia de género, la propia coherencia interna del relato de quien afirma ser víctima, su grado de exhaustividad y su persistencia en el tiempo son suficientes para dar por acreditada la hipótesis acusatoria ${ }^{65}$.

Con lo razonado con anterioridad en este trabajo puede descartarse el peso justificativo de este argumento. En suma, la virtualidad probatoria de un relato no puede verificarse ni contrastarse sobre la base del mismo relato; esa verificación ha de encontrar apoyo en elementos externos. En esta misma línea, la psicología del testimonio reconoce que el análisis de la credibilidad del contenido de una declaración basado en criterios internos se basa en un presupuesto metodológico, la existencia de diferencias intrínsecas entre las declaraciones reales y las falsas-imaginadas-sugeridas, seriamente cuestionado ${ }^{66}$. Así, se afirma que los análisis estadísticos realizados no son lo suficientemente exactos como para ser admitidos como prueba científica, que el

65 Véase Di Corleto, J., (2017): 285 y ss.

66 Manzanero, A., 2010: 245. 
porcentaje de error de este tipo de análisis es superior al tolerable o que se trata de instrumentos no ampliamente aceptados por la comunidad científica ${ }^{67}$.

No niego la relevancia de la coherencia del relato, pues si, como dijimos con anterioridad, la acción central afirmada es claramente identificable y se enmarca en un contexto que proporciona una explicación aceptable del comportamiento de los sujetos que intervienen en ella habría razones lógicas para tomar en serio dicho relato. Sin embargo, por sí sola, la coherencia en la narración es insuficiente, también en los delitos de violencia de género, pues la mayor o menor fiabilidad de una fuente de prueba no depende del tipo de hipótesis delictiva a probar. Por último, no está de más recordar que, especialmente en el caso de víctimas de género especialmente vulnerables, v.gr. en casos de enfermedad mental, estas pueden realizar relatos, en apariencia poco coherentes en múltiples detalles, que, no obstante, encuentren respaldo en aspectos sustanciales que permitan la acreditación del hecho nuclear.

\subsection{La existencia de una situación de asimetría o dominación}

En relación con lo anterior, se señala que existen ciertos datos contextuales que permiten inclinar la balanza en favor del testimonio, muy especialmente la existencia de una relación asimétrica de poder entre quien afirma ser víctima y el acusado.

El aserto deja intacta la crítica realizada anteriormente, pues, por lo general, el supuesto de hecho (la existencia en el caso concreto de una relación de dominación) no puede presumirse sin más en el caso a enjuiciar ${ }^{68}$ y, por tanto, debe ser justificada a través de alguna fuente de prueba ajena a la declaración de la testigo, aun indiciaria. De ser así, ya no nos encontraríamos en el supuesto del testimonio único no corroborado, pues podría constatarse la presencia de un elemento corroborador.

Por esta razón, líneas jurisprudenciales como la contenida en la Sentencia del Pleno de la Sala II del Tribunal Supremo núm. 677/2018, de 20 de diciembre pueden tener un impacto paradójico. La sentencia referida consolida una interpretación de determinados delitos cometidos en el ámbito de la violencia de género en el sentido de no exigir como elemento para apreciar la tipicidad que el hecho denote la existencia de esa relación de dominación, por presumirse normativamente inherente a toda agresión física de un hombre sobre una mujer. Siendo perfectamente aceptable esa interpretación de la normativa sustantiva, por ser compatible con el tenor literal de la ley, y el propósito del legislador que introdujo dichos tipos penales en la Ley Orgánica 1/2004, de 28 de diciembre, de Medidas de Protección Integral contra la Violencia de Género, el riesgo es que acabe desincentivando al investigador para que

67 Véase Ramírez Ortiz, J. L., 2018.

${ }^{68}$ A título de ejemplo: es evidente que un empleador poderoso y su empleada, que vive en situación precaria, se encuentran en posiciones asimétricas, pero los datos probatorios que evidencien que nos encontramos ante un empleador poderoso y una empleada que vive en situación de precariedad deben provenir de fuentes ajenas a la sola declaración de la testigo. 
busque e incorpore información de contexto sobre la relación, que pueda servir para dar respaldo al testimonio de la víctima y, con ello, se pierda riqueza acreditativa de interés para la justificación del hecho en sí.

En conclusión, la perspectiva de género no permitiría eludir o vadear los problemas epistemológicos y procesales que en el enjuiciamiento plantea el testimonio no corroborado, pues una valoración del testimonio no estereotipada, a lo sumo, permitiría afirmar, en perspectiva interna, la coherencia del relato de la víctima, pero no su fiabilidad, que seguiría precisando de datos objetivos externos verificables.

\section{FUNCIÓN EPISTÉMICA Y FUNCIÓN HEURÍSTICA DE LA PERSPECTIVA DE GÉNERO}

\subsection{La perspectiva de género: sesgos y estereotipos}

Los sesgos cognitivos, también conocidos como procedimientos heurísticos, son aquellas reglas que, de modo inconsciente, todas las personas aplicamos al procesar la información que recibimos del exterior y que permiten reducir las tareas complejas de asignar probabilidades y predecir valores a operaciones de juicio más simples. Como parte de la herencia genética humana, estos sesgos se encuentran siempre presentes, y permiten agilizar el proceso de toma de decisiones cuando percibimos y analizamos una determinada situación.

En el ámbito del proceso y las decisiones judiciales Muñoz Aranguren ${ }^{69}$ destaca, entre otros, los siguientes: a) Sesgo de la representatividad. A través del mismo las personas toman decisiones en función de aquello que ya conocen y les resulta parecido a lo que tienen que decidir; $b$ ) Sesgo de la disponibilidad. Mediante este «atajo mental» el sujeto procede a valorar la probabilidad de que acaezca un suceso, tomando en consideración la facilidad con la que el propio sujeto puede recordar o imaginar ejemplos de sucesos similares; c) Sesgo de anclaje y ajuste. Mediante este procedimiento, el sujeto realiza una estimación a partir de un valor inicial (anclaje) que, posteriormente, va adecuando a medida que obtiene nueva información adicional. Por lo general, la valoración inicial suele ejercer una influencia indebida en el análisis del sujeto, que la ajusta a la información que va recibiendo sin cambiarla; d) Sesgo de confirmación. En este procedimiento el sujeto tiende a filtrar la información que recibe buscando y sobrevalorando las pruebas y argumentos que confirman su posición inicial, e ignorando las pruebas y argumentos que no la respaldan; e) Sesgo de grupo. Mediante este procedimiento, el sujeto valora de forma homogénea las acciones y opiniones de las personas que pertenecen al mismo grupo, por la sola razón de pertenencia a ese grupo. Esos prejuicios pueden ser tanto positivos, como negativos.

${ }^{69}$ Muñoz Aranguren, A., 2011. También los analiza en detalle Nieva Fenoll, J., 2010: 120 y ss. 
Por lo que nos ocupa, este último sesgo adquiere gran relevancia y se vincula con el concepto de estereotipo, entendido como preconcepción sobre las características de los miembros de un colectivo o sobre los roles que deben cumplir. La presencia del estereotipo, además, incide en el resto de heurísticos, pues el trasfondo cultural machista del juez puede determinar en gran medida el contenido concreto de aquéllos y condicionar fuertemente el sentido de la decisión del caso sometido a su consideración. Los estereotipos de género, concebidos como grupo estructurado de creencias sobre los atributos personales de hombres y mujeres ${ }^{70}$, implican una variedad de aspectos tales como las características de la personalidad, comportamientos y roles, características físicas y apariencia u ocupaciones y presunciones sobre la vida y orientación sexual. Como construcciones ideológicas y culturales reflejan la estructura desigual de poder existente en la relación entre sexos y pueden desempeñar una función no solo descriptiva sino también prescriptiva en tanto implícitamente imponen a las mujeres que se adecuen a los roles que se les asignan.

Respecto de su tipología, Cook y CusaCK ${ }^{71}$ distinguen entre estereotipos de sexo (centrados en los atributos y diferencias físicas y biológicas existentes entre hombres y mujeres, v.gr. los hombres son físicamente más fuertes que las mujeres), estereotipos sexuales (basados en las características o cualidades sexuales que deberían ser poseídos por hombres y mujeres, v.gr., la sexualidad de las mujeres se vincula a la procreación), estereotipos sobre los roles sexuales (fundados en el papel que se atribuye o espera de hombres y mujeres, v.gr. las mujeres tienen un rol de cuidadoras en la familia) y estereotipos compuestos o aquellos que combinan varios estereotipos de género.

La vinculación entre heurísticos y estereotipos salta entonces a la vista. En suma, un juez que haya naturalizado el estereotipo sobre el rol de la mujer como cuidadora (cuyo ámbito por definición es el doméstico, atendiendo las necesidades de padres, hijos y esposos) y el estereotipo sexual de que la sexualidad de la mujer está destinada a la procreación, de partida tenderá a infravalorar el valor probatorio de la declaración de una mujer dedicada a la prostitución que denuncia una violación, por lo que interpretará las pruebas, aun inconscientemente, buscando datos que confirmen sus preconcepciones (sesgo de confirmación), de modo que aun cuando reciba informaciones nuevas tenderá a ajustarlas a su estimación inicial (sesgo de ajuste). Y, lógicamente, la decisión que tome, basada en la valoración sesgada del testimonio, que creerá correcta, especialmente si no es corregida por vía de recurso, repercutirá en sus decisiones futuras (sesgos de representatividad y de la disponibilidad).

\subsection{Función epistémica y función heurística de la perspectiva de género}

A tenor de las precedentes consideraciones, parece claro el papel que la perspectiva de género puede desempeñar en el ámbito de la disciplina probatoria, en tanto

70 Seguimos a Cook, R., y Cusack, S., 2009.

71 Ibid. 
que permite al juzgador identificar los estereotipos subyacentes en sus evaluaciones, tomar conciencia de la posibilidad de que hayan tenido incidencia en los procedimientos heurísticos a los que recurre inadvertidamente, y hacer uso de la información que proporciona este punto de vista para valorar sin prejuicios la prueba practicada. Servirían así como máximas de la experiencia de indudable valor epistémico, en tanto que aportarían criterios cognoscitivos sobre la base de los cuales realizar inferencias, sin reproducir los roles inherentes a la distribución asimétrica de poder existente entre hombres y mujeres. Ciertamente, habrá ocasiones en que la realidad de lo sucedido se ajuste al estereotipo socialmente vigente, pero de lo que se trata es de hacerlo aflorar, de verbalizarlo, de ser consciente de su presencia, para evitar que determine, injustificadamente, reconstrucciones históricas erróneas y reproductoras de la desigualdad.

No obstante, no debe sobrevalorarse dicho valor epistémico. Como refiere TA$\mathrm{RUFFO}^{72}$, hay máximas de la experiencia que se basan en generalizaciones que pueden considerarse válidas universalmente (generalmente, con fundamento en conocimientos científicos), en cuyo caso cabe construir una inferencia de tipo deductivo. Próximas a ellas son las máximas que no expresan una ley general, sino que se basan en una cuasigeneralización, es decir, en la expresión de una tendencia que tiene determinado hecho a ocurrir con ciertas modalidades, por lo que puede ser prácticamente equiparada a una verdadera generalización, en atención a los tolerables márgenes de error. Las más frecuentes son aquéllas máximas que carecen de ese fundamento científico general o cuasigeneral, si bien disponen de base empírica. Por último, hay otras falsas máximas de la experiencia, carentes de confirmación científica o empírica y que no expresan conocimientos, sino que se basan en prejuicios sociales generalizados. Pues bien, la perspectiva de género permite desactivar estas falsas máximas de la experiencia (v.gr. en las relaciones de dependencia laboral las mujeres no padecen situaciones de acoso sexual, quienes denuncian tales hechos son fabuladoras ventajistas), pero no puede convertir algunos de sus enunciados en máximas de la experiencia universal o cuasiuniversalmente válidas (v.gr. en las relaciones de dependencia laboral, las mujeres siempre padecen, o padecen con un altísimo grado de probabilidad, situaciones de acoso sexual, de modo que las mujeres que denuncian tales hechos dicen necesariamente la verdad). Con ello no se minusvalora la utilidad de esas máximas de la experiencia actualizadas, sino que se les otorga su verdadero valor (v.gr. en relaciones de dependencia laboral suelen producirse con relativa frecuencia situaciones de acoso sexual). Y su virtualidad, que ha de trasladarse a la motivación probatoria, radica en que facilita una apreciación sin prejuicios de género de la prueba, posibilitando que la evaluación de la conducta humana se adecue al contexto económico y sociopolítico concreto (lo que vincula esta perspectiva a la perspectiva de clase social, muy descuidada) y a las circunstancias particulares de cada sujeto interviniente, como víctima o victimario, en el hecho penalmente relevante.

\footnotetext{
72 TARuffo, M., 2006: 439 y ss.
} 
Ahora bien, según la tesis que defiendo, en casos de testimonio único no corroborado, en el momento del enjuiciamiento tal perspectiva carece de utilidad, dada la insuficiencia estructural de dicha prueba para desvirtuar la presunción de inocencia.

Sin embargo, como también señala TARUfFo, las máximas de la experiencia (y, por tanto, también las que suministra la perspectiva de género, podemos añadir) despliegan otra función central: pueden y debe servir para formular hipótesis adecuadas sobre los hechos de la causa (función heurística), indicando al investigador qué datos fácticos ha de incorporar, para lo que habrá de acudir, partiendo de un minucioso y no estereotipado examen de la declaración de la víctima, a las correspondientes fuentes probatorias que le servirán de respaldo en el futuro juicio oral. De este modo, además, podrá prevenirse el riesgo de impunidad para el caso de que, cuando proceda, en juicio la víctima opte por acogerse al derecho que le otorga el art. 416 Lecrim, que le dispensa de declarar en contra de su pareja, al tiempo que se la releva de la carga emocional que supone el saberse fuente única de prueba para la condena del agresor.

En la práctica judicial sucede con relativa frecuencia que, en juicios por delitos de violencia de género los medios de prueba propuestos a practicar se reduzcan a los testimonios de denunciante y acusado. En algunos casos, además, se dispone de un solo elemento externo de confirmación (un dictamen pericial forense que identifica signos lesivos), pero cuando el dato probatorio resultante de dicho informe es reconducible también a la hipótesis exculpatoria, atendido el contenido de la declaración de la persona acusada, la polivalencia del dato (en tanto que compatible en igual grado con la hipótesis acusatoria y la exculpatoria) puede acabar provocando un déficit de prueba de cargo insalvable.

Con todo, ello no siempre ocurre, frente a lo que suele alegarse, por la propia naturaleza de los hechos ${ }^{73}$. Lo cierto es que en tales casos suelen existir numerosos elementos indiciarios de gran valor acreditativo que pueden acumularse a la declaración del testigo que afirma ser víctima y que permiten, por su riqueza y a la luz de la perspectiva de género, una adecuada reconstrucción histórica del suceso de forma respetuosa con las exigencias que impone el derecho que consagra el art. 24.2 CE. Lo que pasa, por desgracia, es que los sujetos institucionales encargados de la investigación suelen prescindir de tales elementos, por no afectar directamente al «hecho nuclear». Sin embargo, a poco que se reflexiones sobre ello, tal circunstancia es consustancial a la prueba indiciaria, que recae, ciertamente, sobre hechos accidentales, pero que permite inferir el hecho principal sobre la base de inferencias. La perspectiva de género puede desempeñar una función esencial en este ámbito, identificando la posible presencia de estereotipos, para descartarlos, así como la de los datos informativos relevantes que pueden obtenerse de la declaración de la víctima durante la fase de investigación, que hacen coherente y congruente su relato, e indican el camino que ha de seguirse para la búsqueda e incorporación a la causa del material investigativo externo que lo corrobore.

73 Suele decirse que, por tener lugar en el ámbito de la privacidad, fuera de la vista de otras personas, no disponen de otros medios probatorios más que las declaraciones de las personas implicadas. 


\subsection{Estereotipos en el enjuiciamiento}

La sentencia dictada por el Tribunal Supremo de Canadá en el caso R.vs. Ewanchuk 74 suele citarse como ejemplo de valoración estereotipada de la prueba por razones de género. El Tribunal de instancia absolvió al acusado de un delito de agresión sexual. Según quedó acreditado, la denunciante acudió a una entrevista de trabajo que tuvo lugar en el interior de la camioneta del acusado. Tras la entrevista, que se desarrolló con normalidad, el acusado invitó a la denunciante a ver algunos de sus trabajos, que tenía guardados dentro de un remolque situado tras la furgoneta. Tras pasar, aquella dejó la puerta del remolque abierta, pero el acusado la cerró de modo que la denunciante pensó que había echado la llave, lo que provocó que sintiera temor. El acusado comenzó a acariciar a la denunciante de forma íntima, pese a que ella verbalizó su oposición (empleando la palabra «no»), en diversas ocasiones. Sin embargo, aquel continuó con los tocamientos de contenido sexual. La sentencia de instancia, pese a considerar probado tal relato, afirmando que la denunciante era una testigo creíble y que había dado un testimonio convincente, absolvió al acusado estimando que había existiendo un "consentimiento tácito». En suma, si bien aceptó la versión de la denunciante, explicativa de que no quería tener relaciones sexuales con el acusado, y que dijo «no» en varias ocasiones, pero que se quedó inmóvil ya que tenía miedo de que aquel pudiera cometer un delito sexual más grave, consideró que su conducta pudo generar una duda razonable en el acusado acerca de si había consentido la relación. La decisión fue ratificada por el Tribunal de Apelaciones de Alberta. La Corte Suprema revocó la revocó y condenó por unanimidad al acusado como autor de un delito de agresión sexual con el argumento de que el «consentimiento implícito o tácito» no era una razón jurídica operativa. En suma, o había consentimiento o no lo había, y las circunstancias concurrentes exigían que el acusado fuera consciente de su inexistencia.

La sentencia de la Corte contiene un voto particular concurrente de la magistrada Sra. L'Hereux-Dubés, que detecta los estereotipos presentes en la valoración realizada en la instancia. Así, señala cómo en dicha valoración late el rechazo hacia la autodeterminación sexual de las mujeres bajo la falsa asunción de que se encuentran siempre en un estado de permanente disponibilidad sexual hacia los hombres. En síntesis, identifica los siguientes estereotipos sexuales: a) las mujeres son pasivas sexualmente y, por tanto, están siempre dispuestas a aceptar las proposiciones de los hombres; $b$ ) las mujeres deben resistirse activa y físicamente a las agresiones sexuales, de modo que, de no hacerlo, se entiende que las consienten; $c$ ) las mujeres se encuentran en un estado de consentimiento permanente frente a la actividad sexual, por lo que cuando dicen «no», en realidad dicen «sí», «inténtalo de nuevo» o «convénceme».

En este caso resultaba evidente la existencia de dichos estereotipos, que llegan a explicitarse en la ponencia del magistrado McClung, de la Corte de Apelaciones de Alberta, en la que destaca que la denunciante pudo provocar al acusado por el modo

\footnotetext{
${ }^{74}$ Puede consultarse en https://scc-csc.lexum.com/scc-csc/scc-csc/en/item/1684/index.do
} 
en que iba vestida, que la acción del acusado fue menos criminal que «hormonal» o que la agresión podía haber terminado fácilmente mediante una "bofetada en la cara» o un "rodillazo bien dirigido»; argumentos en los que subyacen dos máximas de la experiencia erróneas: los hombres no pueden controlar su instinto sexual y toda mujer que quiere evitar una agresión sexual empieza por pelearse con el agresor.

Ahora bien, en el caso, además de los datos de hecho directos (la negativa reiterada mediante el empleo de la palabra «no», no discutida) existían otros datos fácticos indiciarios o indirectos que evidenciaban la falta de consentimiento. Así, los denotativos de la situación de asimetría (la víctima, que había acudido en búsqueda de empleo, contaba tan solo con 17 años de edad y el acusado era una persona que la doblaba en estatura) y de contexto (los hechos suceden tras la entrevista de trabajo a la que acude aquella sin conocer previamente al acusado, dentro de un remolque cuya puerta, debido a la acción de aquel, la primera estimaba que estaba cerrada).

Con todo, la praxis demuestra que no siempre nos encontramos ante casos en los que disponemos de datos probatorios tan nítidos. Es en los casos límite (donde se dispone únicamente de la testifical no corroborada de quien afirma ser víctima o, en su caso, también de la declaración de la persona acusada de signo contrario) en los que la virtualidad de la perspectiva de género no permite superar el test de suficiencia que exige la presunción de inocencia, pero en los que puede servir para indicar al investigador la «hoja de ruta» que ha de seguir para orientar la indagación y hacer acopio de material probatorio.

\subsection{Estereotipos en la investigación}

\subsubsection{Corte Interamericana (casos Campo Algodonero contra México y Rosendo Cantú contra México)}

El caso prototípico de déficits en la investigación debidos, entre otras razones, a la falta de perspectiva de género es el contemplado en la sentencia de la Corte Interamericana de Derechos Humanos (en lo sucesivo, Corte IDH) del 16 de noviembre de 2009 dictada en el caso González y otras (Campo Algodonero) vs. México, referido al asesinato de ocho mujeres en Ciudad Juárez y a las graves irregularidades producidas y falta de diligencia constatada durante las pesquisas. La sentencia de la Corte declaró, por ello, la responsabilidad internacional del Estado demandado y le instó a reconducir adecuadamente el proceso ${ }^{75}$.

75 Así, señala: «La Corte considera que ante tal contexto surge un deber de debida diligencia estricta frente a denuncias de desaparición de mujeres, respecto a su búsqueda durante las primeras horas y los primeros días. Esta obligación de medio, al ser más estricta, exige la realización exhaustiva de actividades de búsqueda. En particular, es imprescindible la actuación pronta e inmediata de las autoridades policiales, fiscales y judiciales ordenando medidas oportunas y necesarias dirigidas a la determinación del paradero de las víctimas o el lugar donde puedan encontrarse privadas de libertad. Deben existir procedimientos adecuados para las denuncias y que éstas conlleven una investigación efectiva desde las 
En concreto, se reprochó al Estado la tardanza y la desidia en el arranque de las investigaciones, motivada, entre otras causas, por estimaciones sexistas sobre las víctimas. Así, según refieren los familiares, los funcionarios que recibieron las denuncias les respondían con explicaciones tales como: $a$ ) «No está desaparecida, anda con el novio o anda con los amigos de vaga»; $b$ ) «Si le pasa eso es porque se lo busca, porque una nińa buena, una mujer buena está en su casa»; $c$ ) «Seguro que se ha ido con el novio, porque las muchachas son muy voladas y se les aventan a los hombres»; d) «Todas las niñas que se pierden...se van con el novio o quieren vivir su vida solas».

Esos comentarios, unidos al hecho de que los investigadores preguntaban a los familiares sobre las "preferencias sexuales» de las víctimas, ponían de relieve el acusado sesgo sexista de los investigadores, que no tomaron en consideración la doble discriminación sufrida por aquellas dado el grupo al que pertenecían, mujeres jóvenes trabajadoras de sectores pobres en Ciudad Juárez.

Una situación similar, de desaparición y muerte violenta, abordó la Corte IDH en el caso Veliz Franco y otros contra Guatemala, resuelto en 2014, en el que las autoridades encargadas de la investigación gestionaron deficientemente la indagación partiendo de inaceptables estereotipos. Así, afirmaron que la víctima era «una cualquiera, una prostituta» y que había sufrido «inestabilidad emocional por andar con varios novios y amigos». La forma de vestir, la vida social y sexual, y la falta de supervisión parental incidieron en actuación ineficaz de las autoridades, que restaban gravedad a los hechos.

Es evidente que los casos citados no eran casos de testimonios únicos en el arranque de la investigación, pero los hemos reseñado por la especial relevancia que tienen en tanto paradigmas de un patrón general de negligencia y falta de efectividad en las investigaciones derivado de una perspectiva estereotipada sobre los roles de las mujeres en la sociedad.

Otro ejemplo concreto de este patrón, en el que, además, existía un testigo que afirmaba ser víctima es el caso Rosendo Cantú y otra contra México, resuelto por sentencia de la corte de 31 de agosto de 2010. La denunciante, mujer indígena de 17 años de edad en el momento de los hechos, fue interrogada por ocho militares y, posteriormente, violada por dos de ellos. Las investigaciones, remitidas a la jurisdicción penal militar por la fiscalía, tras la denuncia de la víctima, fueron archivadas por inexistencia de pruebas de la realidad de los hechos denunciados. La lectura de la sentencia de la Corte es recomendable, pues declaró probada la violación, a los efec-

primeras horas. Las autoridades deben presumir que la persona desaparecida está privada de la libertad y sigue con vida hasta que se ponga fin a la incertidumbre sobre la suerte que ha corrido". Y, a este respecto, añade: "Además, la Corte considera que el Estado no demostró haber adoptado normas o implementado las medidas necesarias, conforme al artículo 2 de la Convención Americana y al artículo 7.c de la Convención Belém do Pará, que permitieran a las autoridades ofrecer una respuesta inmediata y eficaz ante las denuncias de desaparición y prevenir adecuadamente la violencia contra la mujer. Tampoco demostró haber adoptado normas o tomado medidas para que los funcionarios responsables de recibir las denuncias tuvieran la capacidad y la sensibilidad para entender la gravedad del fenómeno de la violencia contra la mujer y la voluntad para actuar de inmediato». 
tos propios de la jurisdicción del Tribunal, poniendo de relieve, a tal efecto, que «Los estándares o requisitos probatorios (de esta Corte) no son los de un tribunal penal, dado que no le corresponde a esta Corte determinar responsabilidades individuales penales ni valorar, bajo tal criterio, las mismas pruebas». Con todo, los datos que la sentencia constata evidencian que existía material fáctico suficiente para el arranque de la indagación y que, de haberse incoado esta, se hubiera podido recopilar material investigativo relevante para la posterior prosecución del proceso. Así, inicialmente se disponía de la declaración testifical de la víctima, de la declaración testifical de referencia de su cónyuge, a quien inmediatamente relató lo sucedido, y del resultado de una primera exploración física que detectó ciertos signos de violencia (aunque estos últimos no hubieran sido necesarios para dar respaldo al testimonio de la denunciante, dado el contexto coactivo en el que se produjo la agresión). Igualmente, existían datos circunstanciales de interés: la presencia de efectivos militares en la zona en el momento de los hechos y la existencia de una praxis institucionalizada de lo que la Corte denomina «violencia institucional castrense» respecto de mujeres de comunidades indígenas que residen en municipios de gran marginación y pobreza, realidad que debería haber servido de hipótesis de trabajo para el investigador. En el curso del procedimiento ante el Tribunal, además, se incorporaron otros elementos de convicción (entre otros, dictámenes periciales psicológicos sobre la existencia de secuelas en la víctima).

La sentencia explica adecuadamente la causa de ciertas inconsistencias encontradas en los relatos de la víctima teniendo en cuenta, a) que los hechos referidos por ella se relacionan a un momento traumático sufrido por la misma, cuyo impacto puede derivar en determinadas imprecisiones al rememorarlos; $b$ ) que tales relatos, además, fueron dados en diferentes momentos desde 2002 a 2010; y, c) que en el momento de los hechos la señora Rosendo Cantú era una niña. Por último, reseña determinadas circunstancias que refuerzan la credibilidad del testimonio, como el hecho de que la menor, que residía en una zona montañosa aislada, tuviera que caminar varias horas para ser asistida por las agresiones físicas sufridas, y para denunciar la violación sexual ante diversas autoridades que hablaban un idioma que ella no dominaba, y que su denuncia era previsible que tuviera repercusiones negativas en su medio social y cultural provocando un posible rechazo de su comunidad. Asimismo, persistió en su denuncia, siendo conocedora de que en la zona en la que vive continuaba la presencia de militares, entre los que podían encontrarse aquellos a los que había denunciado.

\subsubsection{Tribunal Europeo de Derechos Humanos (caso M.C. contra Bulgaria)}

El leading case en materia de evaluación de la perspectiva de género a la hora de identificar los elementos de los delitos contra la libertad sexual y evaluar la información aportada por una víctima doblemente discriminada (en el caso, mujer y menor) en el ámbito del Consejo de Europa es, sin duda la sentencia del TEDH de 4 de diciembre de 2003, dictada en el caso M.C. contra Bulgaria. La demandante, de 14 ańos y 10 meses de edad y, por tanto, apta para prestar consentimiento para man- 
tener relaciones sexuales conforme a la ley búlgara, alegó haber sido violada en dos ocasiones en dos días consecutivos por dos jóvenes de 20 (A) y 21 (B) años, amigos entre sí y conocidos por ella, y encontrándose con ellos un tercero $(\mathrm{C})$. En la primera ocasión, en el coche de uno de los agresores (A), en un lugar solitario, encontrándose en las proximidades $\mathrm{B}$ y $\mathrm{C}$, y en la segunda, en el domicilio del C, por otro agresor, B, encontrándose en la casa A. En ambos casos la víctima tuvo miedo, pero verbalizó su oposición, lo que no sirvió de nada. Encontrada por su madre en la mañana del segundo día, la menor le contó la primera agresión, ocultándole la segunda por vergüenza, al haberse educado en una atmósfera conservadora, vivir en un pequeño pueblo donde todos se conocían, y tratarse de su primera relación sexual. Ambas fueron al hospital donde la menor fue reconocida y se constató que su himen había sido rasgado recientemente. Igualmente se localizaron erosiones leves en el cuello y otras partes de su cuerpo. Según relata la demanda, el autor de la primera violación habría visitado a la menor en su domicilio, pidiéndole perdón y diciéndole a su madre que tenía intención de contraer matrimonio con ella, lo que, en un principio habría sido aceptado por la madre como forma de minimizar el alcance de lo sucedido. Sin embargo, días más tarde, la madre se enteró de la segunda violación. Entonces, ambas denunciaron los hechos. Los denunciados fueron detenidos, y alegaron que ambos habían mantenido relaciones sexuales con la menor.

La policía realizó varios actos investigativos (recibió declaración a los denunciados, a la menor, a su madre, a testigos de descargo de la defensa, contó con el reconocimiento médico y, a instancias de la fiscalía, pues previamente había archivado el caso, realizó una pericia psicológica a la víctima por especialistas que concluyeron que la reacción de esta fue normal, considerando su edad y circunstancias personales). Finalmente, la fiscalía archivó el caso estimando que no había evidencia de que la víctima hubiera opuesto resistencia, por lo que, tomando en consideración las pruebas declarativas, el uso de la fuerza o las amenazas no quedaban justificadas «más allá de una duda razonable». A pesar de los recursos interpuestos, la decisión fue confirmada.

La sentencia del TEDH concluyó que el Estado búlgaro había vulnerado los arts. 3 y 8 del CEDH (prohibición de los tratos inhumanos y degradantes y derecho a la vida privada). En primer lugar, el Tribunal recordó que recae sobre los Estados parte la obligación de tipificar el delito de agresión sexual y de realizar investigaciones efectivas cuando se denuncian. Tras hacer un estudio de derecho comparado, señaló también que el cumplimiento de esa obligación pasaba por la efectiva penalización de todo acto sexual no consentido, incluso en ausencia de amenazas, fuerza física o resistencia de la víctima, por lo que destacó que, en el ámbito de la persecución de estos delitos, cualquier aproximación rígida que requiriese la aportación de pruebas de la existencia de resistencia física en cualquier circunstancia, vulneraría el Convenio. En el caso concreto, si bien puso de relieve que la legislación búlgara no exigía la existencia de fuerza física para estimar cometido el delito de agresión sexual, estimó que en su aplicación práctica la había impuesto, pues, en ausencia de pruebas del uso de la fuerza y de resistencia activa de la víctima o llamadas de auxilio, se había estimado 
que la hipótesis inculpatoria carecía del suficiente respaldo. Señaló que en este tipo de delitos, los investigadores han de centrarse en la búsqueda de pruebas de la existencia o no de consentimiento y no en la de la fuerza o resistencia. No se habían tomado, así, en consideración, ni tampoco investigado todas las circunstancias concurrentes (el número y edad de los implicados como denunciados, los lugares solitarios en los que se habrían cometido los hechos, la especial vulnerabilidad de la menor, la natural reacción de ésta en los primeros momentos o el resultado del informe psicológico), ni se habrían tratado de refutar los testimonios de descargo sospechosos presentados todos por los investigados, testimonios que la demandante había denunciado como falsos. Además, podemos añadir, se había impuesto un estándar probatorio muy exigente para continuar la causa (el de la presunción de inocencia), impropio de esta fase procesal. Y, sobre todo, no se trataba, frente a lo que los investigadores erróneamente estimaron, de un supuesto de testimonio único contradicho por las versiones opuestas de los investigados, pues existían múltiples datos provenientes de fuentes diversas que convergían en la dirección inculpatoria, y que habrían exigido la continuación de las indagaciones.

\subsubsection{Un modelo investigativo no estereotipado}

Antes de proseguir, conviene introducir una matización. El fenómeno de la «globalización» de los derechos humanos provoca un permanente diálogo transnacional entre numerosos operadores jurídicos sobre la base de un lenguaje común que se va construyendo gradualmente. Eso puede dar lugar a que durante el diálogo el empleo por un interlocutor de un determinado término cuando da cuenta de su respectiva situación nacional haga pensar al interlocutor de otra procedencia que comparten realidades idénticas, lo que puede no ser el caso. Un déficit de "perspectiva de género» no tiene el mismo alcance en un Estado central que en un país semiperiférico o periférico ${ }^{76}$. El nivel de desarrollo económico y social condiciona indudablemente el número y tipología de hechos delictivos que ingresan en el sistema penal. Y su tratamiento, una vez acceden a él, varía también en función de esos grados de desarrollo, que suelen corresponderse con los grados de implantación de la imparcialidad, eficacia y profesionalidad en los investigadores e independencia en los juzgadores. Hecha esta salvedad se comprende que en gran parte de los casos tratados por la Corte IDH junto a la problemática de género se detecten, entre otros, problemas estructurales de pobreza y de corrupción e ineficacia general de los sistemas penales involucrados. Ser consciente de estas diferencias es relevante tanto para diagnosticar adecuadamente la raíz de los problemas como para prescribir soluciones.

Dicho lo anterior, de las resoluciones comentadas cabe inferir a grandes rasgos que una investigación no estereotipada por razón de género exigiría que las indagaciones estuvieran destinadas prioritariamente a la búsqueda de datos investigativos

76 Utilizando la terminología de De Sousa Santos, 2009: 101 y ss. 
que prestaran respaldo al testimonio de quien afirma ser víctima ${ }^{77}$, no descartando la propia investigación sobre la base de prejuicios inducidos por estereotipos de género y no archivándola por aplicación de estándares probatorios impropios de la fase investigativa, en la que en el arranque basta con la posibilidad de la comisión del hecho delictivo y en la prosecución con su probabilidad prevalente.

En esta línea, una investigación diligente debe recopilar datos probatorios provenientes de fuentes distintas a la declaración de la víctima con el objeto de buscar el refuerzo externo de dicha declaración, datos relativos al concreto contexto de producción de los hechos, la específica configuración de la relación de poder, la existencia, en su caso, de antecedentes de violencia, su frecuencia o reiteración, la viabilidad de posibles represalias, el estado anímico y psicológico de la víctima tras los hechos, la existencia de posibles secuelas ${ }^{78}$, la presencia de eventuales testigos de referencia a los que la denunciante haya contado lo acontecido y que también puedan dar fe, como testigos directos, del estado de aquélla al narrar los hechos, la existencia de datos que solo podrían ser conocidos por la víctima de haber sucedido el hecho tal y como lo explica $^{79}$, etc.

En cuanto a la dominación o la superioridad en las relaciones interpersonales, efectivamente cabrá inferirlas en algunos casos de las características propias de las personas implicadas (diferencia de edad, características físicas, psicológicas e intelectuales, nivel académico, estado de salud, posición social, autoridad ejercida, etc.). Pero en otras, habrá que realizar un esfuerzo adicional para incorporar una información como ésta singularmente relevante, dada su utilidad probatoria. Esfuerzo siempre justificado, por cuanto un relato coherente sobre una agresión se ve reforzado si existe prueba externa de que el narrador se encontraba sometido, habitual u ocasionalmente, a la persona a la que denuncia como agresora. Por otra parte, el punto de partida de que en contextos de subordinación son factibles los abusos constituye un modo adecuado de orientar las investigaciones en este tipo de delitos.

Este contexto, además, es especialmente relevante para abordar la prueba de la inexistencia del consentimiento libre y voluntario en aquéllas figuras delictivas en las que dicho elemento forma parte esencial de la estructura típica (en especial, delitos sexuales), pues la ausencia de una negativa clara, expresa y terminante de la denunciante no implica que consienta el acto de que se trate, pudiendo deberse tal falta de oposición a otros motivos vinculados con su situación (v.gr. incapacidad de defenderse, temor a una agresión más grave, miedo a perder el puesto de trabajo del que se depende en exclusiva, etc.).

77 O de quien se afirma que es víctima (casos Campo Algodonero contra México y Rosendo Cantú contra México).

78 Tomando también en consideración las concretas circunstancias del caso, ya que no existe un modelo arquetípico de víctima y en los juicios acerca de cómo ha de ser el comportamiento esperable de la víctima tras el hecho pueden anidar prejuicios de género. Así lo destaca López OrTegA, J. J., 2018: 3 y ss.

79 Por ejemplo, la presencia de un arma de fuego en el cajón de la mesa de noche del agresor sexual. 


\subsection{La dominación: elementos de contexto relevantes}

En el año 2010, los profesionales de los Equipos de Asesoramiento Técnico Penal (EATP) de la Generalitat de Cataluña ${ }^{80}$, publicaron la guía revisada de la evaluación del testimonio en violencia de género ${ }^{81}$. La guía se elaboró sobre la base de la metodología propia del análisis del contenido de las declaraciones basado en criterios. A tal efecto, se identificaron quince criterios indicadores de la veracidad que, sometidos al correspondiente trabajo de campo empírico, se encontraron presentes en la mayor parte de los relatos de personas de las que se sabía que habían sido víctimas de delitos de violencia de género.

Como veremos posteriormente, estas pretendidas periciales de fiabilidad tienen un valor reducido, en especial tratándose de adultos. Sin embargo, pese a ello, algunos de los criterios tomados en consideración gozan de un indudable interés investigativo en cuanto explicitan hechos denotativos de fuertes situaciones de dominación, sobre los que deben proyectarse las investigaciones diligentes para buscar las oportunas fuentes de prueba que los justifiquen. A continuación, enumero algunos de esos criterios, centrados en el ámbito de las relaciones de pareja, pero que pueden extrapolarse, en algunos casos, a otras relaciones (v.gr. acoso sexual en el trabajo).

a) Control amplio masculino cognitivo-conductual.

Se trata de acciones llevadas a cabo por el hombre, de manera directa o indirecta, con la finalidad de someter a la mujer tanto a nivel cognitivo como conductual. Suponen un control sistemático, habitual y abusivo en distintos ámbitos, vigilando sus actos, movimientos, el modo en que viste, escuchando sus conversaciones con terceros, revisando sus comunicaciones, controlando sus llamadas, impidiéndole trabajar fuera de casa y relacionarse con otras personas, buscando el progresivo aislamiento social, familiar y de relaciones de la mujer, pudiendo llegar hasta el control de la propia documentación personal en especial respecto de mujeres extranjeras sin recursos.

b) Descripción contextualizada de microviolencias.

El referente son las prácticas sutiles de dominación del hombre sobre la mujer en la vida cotidiana, aprovechándose de la confianza afectiva, que suelen provocar confusión, culpa y dudas que acrecienten la falta de autoestima de la víctima y acrecientan la sujeción (v.gr: la delegación de todos los trabajos de cuidado, la imposición de demandas abusivas, etc.).

c) Violencia indirecta que suscita temor.

Se trata aquí de agresiones sobre mascotas, objetos de la casa, y amigos o conocidos de la pareja o familia, con la finalidad de atemorizar a la mujer pareja.

d) Estrategias de supervivencia de la mujer.

${ }^{80}$ Quienes suelen intervenir como peritos auxiliares de los tribunales en el ámbito de la Comunidad Autónoma de Cataluña.

81 JuÁreZ, J.J. y otros, 2010. 
Para superar la situación, la mujer intenta ir adaptándose a las nuevas exigencias para evitar el recrudecimiento de la violencia. Así, procura anticiparse a potenciales reacciones violentas, no desagradar, disociar sus propios sentimientos y percepciones para adherirse a los deseos del hombre e identificarse con él, advirtiéndose otras distorsiones cognitivas tales como la negación, la minimización o la normalización de los abusos.

e) Evolución de la violencia y progresión en la asimetría de poder.

Con ello, los autores del estudio se refieren al incremento gradual de la asimetría en el curso del tiempo y de la subordinación violenta, sea física (golpes), psíquica (insultos, vejaciones, desvalorización, etc), o sexual.

f) Temor a represalias.

A través de amenazas explícitas o implícitas, se genera en la mujer el miedo a la reacción del hombre sobre personas, cosas o aspectos de relevancia para aquella.

g) Ambivalencia y ambigüedad hacia el hombre.

Así, las mujeres que padecen violencia de género, suelen presentar pensamientos y emociones contrarias hacia sus parejas, sentimientos contradictorios de amor y odio, autonomía y dependencia, reconociéndose como víctimas pero también como corresponsables de la situación, lo que explicaría las retractaciones en las denuncias, en las decisiones sobre la ruptura de la relación o el mantenimiento de la convivencia.

\section{b) Antecedentes de violencia en la biografía de la víctima}

Aunque no se individualiza como criterio de verdad, se trata de un elemento que reviste interés, pues los estudios realizados han evidenciado que la variable de la exposición a la violencia previa incide sobre el resto de criterios ${ }^{82}$. Así, mujeres familiarizadas con el abuso tienden incorporar la violencia a sus vidas como algo normal, como parte integrante de sus biografías, a infravalorar los riesgos del mantenimiento de la convivencia y a disculpar episodios especialmente graves, circunstancias que pueden explicar que sus relatos parezcan menos genuinos y más pobres al no integrarse como episodios excepcionales en sus historias vitales.

Pues bien, los precedentes hechos, aun cuando no constituyan el hecho principal (v.gr. puede investigarse un hecho concreto de singular gravedad como un homicidio intentado), son hechos secundarios provenientes del aporte de la criminología con perspectiva de género con indudable valor indiciario, que pueden introducirse en el proceso por la vía de las testificales directas (conocidos o familiares que sin haber visto el hecho objeto de acusación, hayan presenciado conductas de control, de violencia indirecta, de estrategias de supervivencia de la víctima), testificales mixtas (de referencia, en cuanto a los datos relatados por la víctima explicativos del temor a las represalias, de la ambigüedad o ambivalencia hacia la pareja, o de la progresión de la violencia, pero directas, en aquellos aspectos percibidos por quienes conversan con

82 Véase en detalle la guía revisada de la evaluación del testimonio en violencia de género ya citada. 
la víctima que ponen de relieve la existencia de signos externos de agresión o signos físicos de dolencias psíquicas), documentales o testificales (respecto de los antecedentes de violencia), documentales (objetos rotos o dañados) o periciales propias (en relación con la existencia de dolencias psíquicas y su posible compatibilidad con el contexto de vida y los hechos punibles investigados).

\section{ALGUNAS FUENTES DE CORROBORACIÓN CONTROVERTIDAS: PERICIALES DE FIABILIDAD Y TESTIFICALES DE REFERENCIA}

Antes de concluir me referiré a dos fuentes de corroboraciones testimoniales a las que suele recurrirse en los delitos de violencia de género. La primera, en mi opinión, sobredimensionada, resulta de dudoso valor. En cambio, la segunda, infrautilizada, puede aportar datos muy relevantes.

\subsection{Pruebas periciales de fiabilidad del testimonio de personas adultas}

Mediante tales pericias se trata de determinar si la declaración es producto de un hecho experimentado por el testigo o producto de la fantasía o la sugestión. Para ello, se parte de un concreto presupuesto metodológico: las declaraciones de sucesos reales (autoexperimentados) difieren de las declaraciones de sucesos falsos (imaginados, sugeridos...) en una serie de características. Como es sabido ${ }^{83}$, estas pericias utilizan dos técnicas combinadas. Por un lado, la técnica CBCA (análisis del contenido de las declaraciones basado en criterios), que evalúa la credibilidad de las manifestaciones emitidas mediante el examen de diversos criterios de contenido que sirven como indicadores de la veracidad de la declaración. Además, se utiliza la técnica SVA (evaluación de la validez de la declaración), concebido como procedimiento de diagnóstico global que incluye los resultados de la técnica CBCA, la información biográfica del sujeto, las puntuaciones a diferentes tests que ha de cumplimentar, y otros indicadores de conducta, como la existencia de elementos externos de corroboración resultantes del expediente judicial.

Pues bien, si el presupuesto metodológico de la técnica CBCA está científicamente cuestionado respecto de los menores de edad ${ }^{84}$, con mucha mayor razón lo está respecto de los adultos. Y en cuanto a la técnica SVA, el elevado riesgo de error en la interpretación de los datos de evaluación (SVA) está siempre presente. En especial, debido al «sesgo confirmatorio», o sesgo del experimentador que al poner a prueba una sola hipótesis (la existencia del hecho punible afirmado) valora más positivamente los criterios que la confirman frente a los que la descartan. Pero, además, el perito redactor del informe suele examinar el expediente judicial, para contrastar datos, en

83 Entre muchas otras referencias, véase Arce, R.; Fariña, F., y Vilariño, M., 2010.

84 Véanse con más detalle Manzanero, A., 2010 y Ramírez Ortiz, J. L., 2018. 
un momento histórico determinado, por lo que es posible que con posterioridad se hayan incorporado diligencias de otro signo que podrían haber incidido en las conclusiones alcanzadas en el informe. En cualquier caso, cabe extraer dos conclusiones: si el perito solo evalúa el contenido de la declaración, el aporte es irrelevante, pues seguiríamos enfrentándonos al testigo único. Y si analiza otros datos provenientes de fuentes probatorias externas, se excede de su cometido como perito y pasa a enjuiciar el caso, por lo que no sería esa pericia la que aportara el elemento corroborador, sino, en su caso, los elementos externos tomados en consideración por el perito. Además, una pericial cuyo objeto fuera una hipotética reconstrucción del hecho enjuiciado a partir de los datos obrantes en la causa (y de los otros que eventualmente pudieran adquirirse en la realización de la supuesta pericia) tomando en consideración los relatos de acusado y testigo para establecer cuál es el más probable sería ilegítima, pues tales cuestiones son las que constituyen el objeto del proceso penal, cuya característica esencial es la reconstrucción del pasado conforme a reglas (juez imparcial, debate dialógico en condiciones de igualdad, contradicción y racionalidad, resuelto por el juez partiendo de la presunción de inocencia como regla de juicio), de modo que si se prestara valor probatorio a la reconstrucción así realizada por el perito, el «acceso a la verdad» se habría producido prescindiendo de las reglas básicas procedimentales para la toma de la decisión, esto es, los derechos fundamentales, viciando su contenido ${ }^{85}$.

A tales críticas cabe añadir otra que no es imputable tanto a las pericias en sí como a su utilización por los jueces: su sobrevaloración epistémica y semántica por aquellos ${ }^{86}$, quienes suelen otorgarles un valor superior al que tienen al considerarlas prácticamente infalibles por partir de un entendimiento de las mismas conforme al paradigma de la individualización (deductivo) y no el de la verosimilitud (inductivo o probabilístico), y que, además, suelen hacerles decir cosas distintas de las que realmente dicen.

Distinto sería que el objeto de la pericia fuera determinar si la persona examina$\mathrm{da}^{87}$ : a) padece alguna enfermedad mental que le condicione y oriente su discurso hacia la fabulación, b) padece alguna enfermedad mental que le impida percibir correctamente los hechos enjuiciados; c) padece alguna enfermedad mental que le impida prestar testimonio en el juicio así como, $d$ ) concurre alguna situación de análoga significación a las anteriores. Reducido así su objeto a situaciones que afectarían a la credibilidad del testigo en sentido estricto, no podrían oponérsele las precedentes objeciones.

\subsection{Declaraciones testificales de referencia}

Como pruebas indirectas que son no permiten dar por acreditado directamente el hecho referido por el testigo presencial. Pueden ser de especial utilidad para testar la

85 Desarrolla esta certera crítica de raíz habermasiana Camarena Grau, S., 2009: 218 y ss.

${ }^{86}$ Gascón, M., 2013: 183 y ss. Tomo la terminología de la autora, que se refiere a esta doble sobrevaloración en relación con la prueba pericial en general.

87 Camarena Grau, S., 2009: 220 y ss. 
fiabilidad del testimonio, pues si lo que el testigo de oídas afirma que le fue referido por el presencial coincide exactamente con lo que este último explica en el acto del juicio, ello puede ser un indicador de fiabilidad de lo que narra, en especial cuando existen varios testigos de referencia de procedencia diversa y lo que narran es coherente y convergente (v.gr. familiares, desconocidos y agentes policiales).

Pero, además, como ha puesto de relieve Hernández García ${ }^{88}$, lo habitual es que en estos casos la utilidad probatoria no provenga de lo referido por el testigo directo al de oídas sino de lo observado directamente por el testigo de oídas (v.gr. los signos externos de victimización del testigo directo cuando narró los hechos, o el estado de la vivienda en la que, según se denuncia, hubo un altercado). Como indicó la STC 217/1989, de 21 de diciembre: «El testimonio de referencia puede tener distintos grados según que el testigo narre lo que personalmente escuchó o percibió -auditio propio- o lo que otra tercera persona le comunicó -auditio alieno-». En consecuencia, el testigo de referencia puede valorarse, como cualquier otro testigo, en lo que concierne a hechos objeto de enjuiciamiento que haya apreciado directamente y a hechos relativos a la validez o fiabilidad de otra prueba. En este sentido, todo aquello que el testigo percibió de modo directo puede integrar una serie de circunstancias que cabe vincular con el hecho en disputa mediante una conexión inferencial a través de la denominada prueba indiciaria. Con estas matizaciones, es evidente que testificales mixtas de este tipo pueden aportar valiosos datos corroboradores.

\section{CONCLUSIONES}

Creo, por tanto, que la versión racionalista de todo sistema tendencialmente orientado hacia la libre valoración probatoria exige siempre, y con independencia de la clase de víctima y del tipo de delito objeto de enjuiciamiento la corroboración del testimonio de aquélla, sin que los aportes de la perspectiva de género sirvan para incrementar el peso probatorio de tal testimonio. Cuando se constata la existencia de un hecho posiblemente delictivo sobre la base de una declaración testifical no corroborada, es en el ámbito de la investigación en el que deben volcarse los esfuerzos para dar cumplimiento a los compromisos internacionales, pues ni la Convención de las Naciones Unidas sobre la Eliminación de Todas las Formas de Discriminación contra la Mujer (también conocida por sus siglas en inglés CEDAW), de 1979, ni el Convenio de Estambul, ni la Convención Belem do Pará, ni las recomendaciones generales adoptadas por el Comité para la Eliminación de la Discriminación contra la Mujer, establecen estándares probatorios diferenciados para los delitos que constituyen su objeto que flexibilicen o degraden la presunción de inocencia ${ }^{89}$.

A diferencia de otros derechos fundamentales, la presunción de inocencia como regla de juicio que incorpora un determinado estándar probatorio es un derecho

88 Hernández García, J., 2009: 207 y ss.

89 En el mismo sentido, Di Corleto, 2017. 
absoluto: no es modulable ni matizable, ni puede someterse a una ponderación con otros intereses en conflicto, pues ello supondría la destrucción del derecho y, con ello, la demolición de un sistema procesal que se basa en la premisa de que la culpabilidad no tiene existencia ontológica, no existe antes del proceso, sino después de él, y solo puede declararse si la reconstrucción del pasado conforme a las reglas que dimanan de los derechos fundamentales se ha producido tras alcanzar un nivel de certidumbre tal que haga posible afirmar que la hipótesis de la culpabilidad encuentra respaldo más allá de toda duda razonable, lo que ha de explicitarse a través de una motivación intersubjetivamente compartible. No es, por tanto, la flexibilización del estándar probatorio lo que afirman esos textos internacionales, sino el deber de los Estados de llevar a cabo investigaciones diligentes y efectivas para esclarecer los hechos en cuestión. Es ese, en mi opinión, el mejor camino para combatir el fenómeno de la violencia de género. Otros, que implican o pueden implicar el abandono de garantías trabajosamente conquistadas, constituyen una fuente de peligro para nuestro modelo constitucional penal.

\section{BIBLIOGRAFÍA}

Alonso Romero, P., 2008: Orden procesal y garantías entre Antiguo Régimen y constitucionalismo gaditano, Madrid: Centro de Estudios Constitucionales.

Andrés IBÁÑez, P., 2009: «La supuesta facilidad de la testifical» en Prueba y convicción judicial en el proceso penal, Buenos Aires: Hammurabi.

- 2011: "¿Qué cultura constitucional de la jurisdicción?», en Cultura constitucional de la jurisdicción, Bogotá: Siglo del Hombre Editores.

Arce, R.; Fariña, F.; Vilariño, M., 2010: Contraste de la efectividad del CBCA en la evaluación de la credibilidad en casos de violencia de género, "Intervención psicosocial», vol. 19.

Beccaria, C., 1764: Tratado de los delitos y las penas. Edición de 1996, Comares: Granada.

Bentham, J., 1823: Tratado de las pruebas judiciales. ed. de E. Dumont. Edición de 2001, Comares: Granada.

Camarena Grau, S., 2009: "¿Son admisibles con carácter general pruebas de tipo pericial sobre la credibilidad?», en 99 cuestiones básicas sobre la prueba penal, Manuales de Formación Continuada, 51, Madrid: Consejo General del Poder Judicial.

Cook, R., y Cusack, S., 2009: Estereotipos de género. Perspectivas legales transnacionales, University of Pennsylvania Press.

Di Corleto, J., 2017: «Igualdad y diferencia en la valoración de la prueba: estándares probatorios en los casos de violencia de género», en Género y justicia penal, Buenos Aires: Ediciones Didot.

De Sousa Santos., 2009: Sociología jurídica critica. Para un nuevo sentido común en el derecho, Madrid: Trotta.

Diges, M., 2016: Testigos, sospechosos y recuerdos falsos, Madrid: Trotta.

Eymerico, N., 1503: Manual de Inquisidores para uso de las inquisiciones de España y Portugal. Edición de 2010, Valladolid: Maxtor.

Ferrajoli, L., 2006: Derecho y razón, Madrid: Trotta.

Ferrer Beltrán, J., 2003: Prueba y verdad en el derecho, Barcelona: Marcial Pons.

- 2007: La valoración racional de la prueba, Barcelona: Marcial Pons.

GAscón, M., 2013: «Prueba científica. Un mapa de retos», en Estándares de prueba y prueba cientifica, Barcelona: Marcial Pons.

Hernández García, J., 2009: «La violencia intraparental: ¿pueden valorarse las referencias que el pariente efectuó a terceros o a los policías que acudieron en auxilio de la víctima, si la víctima se 
acoge en el acto del juicio a su derecho a no declarar?», en 99 cuestiones básicas sobre la prueba penal. Manuales de Formación Continuada, 51, Madrid: Consejo General del Poder Judicial.

Igartua Salaverria, J.; 1995: Valoración de la prueba, motivación y control en el proceso penal, Valencia: Tirant lo Blanch.

— 2009. El razonamiento en las resoluciones judiciales, Lima-Bogotá: Palestra Temis.

JuÁREZ, J. J. y otros., 2010: Revisió de la guía d'avaluació del testimoni en violencia de gènere (GAT-VIG$R$ ), Barcelona: Centre d'Estudis Jurídics i Formació Especialitzada.

López Ortega, J.J., 2018: «Breves reflexiones: yo sí te creo», en Boletín de la Comisión Penal de Juezas y Jueces para la Democracia, núm. 10, volumen II.

Manzanero, A., 2010: Memoria de testigos: obtención y valoración de la prueba testifical, Madrid: Pirámide.

Mazzoni, G., 2010: ¿¿Se puede creer a un testigo?, Madrid: Trotta.

Montesquieu, C.: 1748: El espiritu de las leyes. Edición de 2002, Tecnos: Madrid.

Muñoz Aranguren, A., 2011: «La influencia de los sesgos cognitivos en las decisiones jurisdiccionales: el factor humano. Una aproximación», en Indret 2/2011.

Nieva Fenoll, J., 2010: La valoración de la prueba, Barcelona: Marcial Pons.

— 2017: «La inexplicable persistencia de la valoración legal de la prueba», en Ars Iuris Salmanticensis Estudios Vol. 5, Salamanca: Ediciones Universidad de Salamanca.

ORTEGo GiL, P., 2015: Entre jueces y reos. Las postrimerías del derecho penal absolutista, Madrid: Dykinson, SL.

Pagano, F., 1803: Principios del Código Penal. Milán. Edición de 2002, Hammurabi: Buenos Aires.

Ramírez OrTiZ, J. L., 2014: «Verdad, proceso y derecho penal (Interrogatorios en la habitación 101)», en Jueces para la Democracia. Información y debate, núm. 79.

— 2018: «La prueba en los delitos contra la indemnidad sexual», en Diario La Ley, núm. 9199, Sección Doctrina, Editorial Wolters Kluwer.

Roberts, P. y Zuckerman, A., 2004: Criminal Evidence, Oxford University Press.

Sancinetti, M., 2013: «Testimonio único y principio de la duda», en Indret 3/2013.

TARuffo, M., 2006: «Consideraciones sobre las máximas de la experiencia», en Páginas sobre justicia civil, Barcelona: Marcial Pons.

Tomás Y Valiente, F., 1993: «In dubio pro reo, libre apreciación de la prueba y presunción de inocencia», en Escritos sobre y desde el Tribunal Constitucional, Madrid: Centro de Estudios Constitucionales.

Vives Antón, T., 2011: Fundamentos del sistema penal, Valencia: Tirant lo Blanch. 
